\title{
FILME COMESTÍVEL À BASE DE AMIDO E MICROINANOFIBRILAS \\ DE CELULOSE DE CENOURA PROLONGA A VIDA ÚTIL DE CENOURA MINIMAMENTE PROCESSADA
}

\author{
ISABELA COSTA GUIMARÃES* \\ EVANDRO GALVÃO TAVARES MENEZES** \\ LUCAS FERREIRA RODRIGUES*** \\ ARIEL COSTA RODRIGUES $* * * *$ \\ ALINE GOMES DIAS PINTO MONTEIRO***** \\ KELEN CRISTINA DOS REIS $S^{* * * * * *}$ \\ EDUARDO VALÉRIO DE BARROS VILAS BOAS*******
}

\begin{abstract}
Este trabalho teve o objetivo de produzir cenouras minimante processadas recobertas com cobertura a base de amido reforçado com micro/nanofibrilas de celulose (MNFC) extraídas da cenoura. Para o processamento mínimo, cenouras previamente sanitizadas com solução de hipoclorito de sódio, foram descascadas, cortadas em rodelas, novamente sanitizadas e centrifugadas. Foram preparadas três coberturas a $3 \%$ de fécula de mandioca, duas delas foram adicionadas de $5 \%$ de MNFC de cenoura, sendo um a $20 \%$ de cenoura (relação da quantidade de água destilada e quantidade de cenoura para o preparo); e o outro a $40 \%$ de cenoura; a última formulação foi preparada sem adição de MNFC de cenoura. Geraram-se quatro tratamentos, sendo T1 composto por cenouras recobertas com cobertura de amido contendo MNFC de cenoura a $20 \%$; T2 composto por cenouras recobertas com cobertura de amido contendo MNFC de cenoura a $40 \%$; C1 contendo cenouras recobertas com cobertura de amido sem MNFC de cenoura e C2 contendo cenouras sem cobertura alguma. O armazenamento das mesmas foi em bandeja de polipropileno em câmara fria. Foram analisadas quanto a perda de massa, sólidos solúveis, acidez titulável, açúcares solúveis totais, $\mathrm{pH}$, ácidos orgânicos, atividade respiratória, pectina total e solúvel, firmeza, cor, atividade antioxidante total, fenólicos totais e análises microbiológicas (fungos filamentosos e leveduras, coliformes totais e fecais e Salmonella sp) a cada 7 dias, durante 28 dias de armazenamento. $O$ uso de cobertura de amido permitiu menor perda de massa em cenouras minimamente processadas, sendo que o reforço com MNFC de cenoura diminuiu ainda mais esta perda. $\mathrm{O}$ uso de cobertura de amido reforçada com MNFC de cenoura foi eficiente para diminuir a taxa respiratória, na prevenção do esbranquiçamento e na manutenção da atividade antioxidante total, quantidade de fenólicos totais e de ácidos orgânicos de cenouras minimamente processadas. As cenouras não apresentaram contagem significativa de fungos filamentosos e leveduras e ausência de Salmonella sp. e de coliformes a 35 e $45^{\circ} \mathrm{C}$, estando assim, livres também de Echerichia coli.
\end{abstract}

PALAVRAS-CHAVE: DAUCUS CAROTA; PROCESSAMENTO MÍNIMO; FILME COMESTÍVEL DE AMIDO; CELULOSE MICROFIBRILADA.

* Engenheira de Alimentos, Mestre em Ciências dos Alimentos - Universidade Federal de Lavras, Professora da Universidade Federal de Viçosa Campus de Rio Paranaíba, e-mail: icostag@yahoo.com.br.

** Engenheiro de Alimentos, Mestre em Ciências dos Alimentos - Universidade Federal de Lavras, Professor da Universidade Federal de Viçosa Campus de Rio Paranaíba, e-mail: evandrogtmenezes@gmail.com.

*** Biólogo - Centro Universitário de Lavras, email: llucasrodrigues@gmail.com.

**** Engenheiro Agrônomo - Universidade Federal de Lavras, email: arielcostaagroufla@hotmail.com.

***** Química, Doutora em Agroquímica, Técnica de laboratório - Universidade Federal de Lavras, email: alinemonteiro@dca.ufla.br.

****** Engenheira Química, Doutora em Ciência dos Alimentos - Universidade Federal de Lavras, email: kelen_ cr@yahoo.com.br.

******* Engenheiro Agrônomo, Doutor em Ciência dos Alimentos, Professor - Universidade Federal de Lavras, email: evbvboas@dca.ufla.br. 


\section{INTRODUÇÃO}

Embora haja grande disponibilidade de produtos vegetais acessíveis a substancial parcela da população brasileira, observam-se níveis inaceitáveis de perdas desses produtos devido a técnicas inadequadas adotadas desde a colheita até o armazenamento. Assim, o processamento mínimo de frutas e hortaliças pode contribuir com a redução de desperdícios, além de possibilitar maior praticidade e economia de tempo no preparo diário de alimentos, cada vez mais necessários ao mundo moderno (ALVES et al., 2010).

O processamento mínimo de hortaliças compreende as operações que eliminam as partes não comestíveis, como cascas, talos e sementes, seguidas pelo corte em tamanhos menores, tornando-as prontas para consumo imediato e mantendo sua condição de produto ao natural (LANA, 2000).

A cenoura (Daucus carota) constitui-se em uma das hortaliças mais produzidas no Brasil, ocupando a quinta posição dentre as mais cultivadas, sendo de grande emprego na indústria de alimentos e podendo ser processada para conserva enlatada, em mistura com outras hortaliças ou também na forma desidratada. O cultivo da cenoura abrange cerca de 28 mil hectares/ano nas diferentes regiões do Brasil (SAPGNOL et al., 2006; STRANGHETTI et al., 2015; PROHORT, 2015). Ela é a principal fonte de origem vegetal em carotenoides provitamínicos $A$, especialmente o a e o $\beta$-caroteno, que podem ser transformados em vitamina A no organismo humano (LIMA et al., 2004).

Cenouras minimamente processadas estão entre as hortaliças mais popularmente consumidas no mundo. No entanto, as operações de processamento mínimo promovem alterações bioquímicas e aceleram a deterioração fisiológica, além de aumentarem os riscos de contaminação microbiológica (RAGAERT et al., 2007). A descoloração causada pela desidratação do tecido e a deterioração microbiana são os principais problemas limitantes da vida útil de cenouras minimamente processadas (EMMAMBUX; MINNAAR, 2003).

O emprego de filmes e coberturas comestíveis à base de biopolímeros (principalmente polissacarídeos e proteínas) em produtos minimamente processados é prática comum na tentativa de estender a vida útil desses produtos, devido ao controle da migração de vapor de água, permeabilidade $\mathrm{ao}_{2}, \mathrm{CO}_{2}$ e migração lipídica em um sistema alimentício, além de reduzir a taxa de respiração por meio da criação de uma atmosfera modificada em torno desses produtos, retardando assim o amadurecimento e a senescência (KROCHTA; De MULDER-JOHNSON, 1997; ALI et al., 2011).

Os nanobiocompósitos são materiais constituídos por uma fase dispersante (contínua), que é o biopolímero, e por uma fase dispersa (descontínua), que é a nanocarga ou a nanopartícula. Em geral, os nanobiocompósitos se referem àqueles constituídos por um único biopolímero ou uma mistura deles com pelo menos um agente de reforço orgânico ou inorgânico que tem uma dimensão nanométrica (MIHINDUKULASURIYA; LIM, 2014). O recobrimento de amido reforçado com MNFC de cenoura proposto no presente trabalho é um exemplo de nanobiocompósito, sendo o amido a fase dispersante e as MNFC de cenoura a fase dispersa. Os nanobiocompósitos exibem elevadas propriedades de barreira e mecânica e melhor resistência ao calor em comparação aos seus biopolímeros puros e compósitos convencionais (RHIM et al., 2013). Azeredo et al. (2009) e Azeredo et al. (2012) estudaram a aplicação de nanofibras de celulose em filmes produzidos a partir de purê de manga e acerola, respectivamente. Em ambas as avaliações foi observada melhora na barreira à perda de água com a adição de nanofibras de celulose.

O objetivo do presente trabalho foi avaliar, ao longo do armazenamento, cenouras minimamente processadas recobertas com cobertura comestível de amido reforçada com micro/ nanofibrilas de celulose extraídas da própria cenoura. 


\section{MATERIAL E MÉTODOS}

\subsection{PROCESSAMENTO MÍNIMO DAS CENOURAS E APLICAÇÃO DAS COBERTURAS DE AMIDO}

As cenouras foram adquiridas no comércio local de Lavras, Minas Gerais, Brasil e transferidas para o Laboratório de Processamento Mínimo de Vegetais do Departamento de Ciência dos Alimentos da Universidade Federal de Lavras, onde foram previamente sanitizadas com solução de $200 \mathrm{ppm}$ de hipoclorito de sódio, por 15 minutos, e resfriadas, a $4{ }^{\circ} \mathrm{C}$, por aproximadamente 12 horas. Então, foram descascadas, cortadas em rodelas de aproximadamente $0,5 \mathrm{~cm}$ de espessura, novamente sanitizadas com solução de $100 \mathrm{ppm}$ de hipoclorito de sódio e centrifugadas.

Coberturas foram preparadas com fécula de mandioca a 3\%, pelo processo de casting, segundo metodologia proposta por Reis et al. (2006). Elaboraram-se três formulações diferentes: duas delas foram reforçadas com MNFC de cenoura a $5 \%$ (em relação à quantidade de amido), sendo que uma foi preparada a $20 \%$ de cenoura (relação da quantidade de água destilada e quantidade de cenoura para o preparo), e a outra, a $40 \%$ de cenoura; a última formulação foi preparada sem adição de MNFC de cenoura.

Para obtenção das MNFC de cenoura, as cenouras foram lavadas e sanitizadas com 200 ppm de hipoclorito de sódio. Foram preparados dois homogenatos, de dois litros cada um, de cenoura com água destilada: um com $20 \%$ e outro com $40 \%$ de cenoura. Primeiramente, as cenouras lavadas e sanitizadas foram raladas e então misturadas à água, e os homogenatos foram preparados com auxílio de um politron (Tecnal, modelo Turratec 102) por aproximadamente 12 horas, com intervalos de 30 minutos entre uma passagem e outra pelo politron. Os homogenatos foram levados para o Laboratório de Nanotecnologia do Departamento de Ciências Florestais da Universidade Federal de Lavras, onde foram processados. O processamento foi realizado em desfibrilador mecânico tipo GRINDER SUPERMASSCOLOIDER ${ }^{\circledR}$ (MKCA6-3, MASUKO SANGYOU Co., Ltda.) com velocidade de trabalho de $1.700 \mathrm{rpm}$ e corrente elétrica de $5 \mathrm{~A}$. Suspensões com aspecto gelatinoso foram obtidas após 40 passagens pelo desfibrilador. As suspensões foram coletadas e armazenadas em ambiente resfriado $\left(4^{\circ} \mathrm{C}\right)$.

As cenouras minimamente processadas foram submetidas a quatro tratamentos diferentes: T1 - cenouras recobertas com cobertura comestível de amido a $3 \%$ reforçado com MNFC de cenoura a 20\%; T2 - cenouras recobertas com cobertura comestível de amido a $3 \%$ reforçado com MNFC de cenoura a 40\%; C1 - controle 1, cenouras recobertas com cobertura comestível de amido a 3\%; C2 - controle 2, sem cobertura. Todas as amostras foram acondicionadas em bandejas rígidas de polipropileno com tampas do mesmo material. Seu armazenamento foi em câmara fria a $4{ }^{\circ} \mathrm{C}\left(+/-0,5{ }^{\circ} \mathrm{C}\right)$ e $90 \%(+/-5 \%)$ de UR. Utilizaram-se três repetições, e cada repetição foi constituída por uma bandeja contendo aproximadamente 100 gramas de cenoura minimamente processada.

\subsection{ANÁLISES REALIZADAS}

As amostras de cenouras minimamente processadas foram analisadas nos dias $0,7,14$, 21 e 28 de armazenamento.

\subsubsection{Perda de massa}

A perda de massa foi calculada como a porcentagem diferencial entre o peso inicial das cenouras no armazenamento e o peso final delas após os dias de armazenamento $(7,14,21$ e 28 dias). Foi utilizada balança semianalítica para a pesagem das cenouras. 


\subsubsection{Sólidos solúveis (SS)}

Foram determinados por refratometria, em refratômetro digital ATAGO PR - $100 \mathrm{com}$ compensação de temperatura automática a $25{ }^{\circ} \mathrm{C}$ (AOAC, 2000), e os resultados foram expressos como porcentagem de SS.

\subsubsection{Açucares solúveis totais (AST)}

Foram extraídos com álcool etílico $95 \%(\mathrm{v} / \mathrm{v})$ e determinados pelo método de antrona (DISCHE, 1962), sendo os resultados expressos em gramas de glucose.100 $\mathrm{g}^{-1}$ de cenoura.

\subsubsection{Acidez titulável (AT)}

A determinação da AT foi realizada por titulação com solução de $\mathrm{NaOH}$ a $0,1 \mathrm{~N}$, de acordo com AOAC (2000), e expressa em porcentagem de ácido málico.

\subsubsection{Determinação do pH}

Foi determinado pelo método potenciométrico em potenciômetro digital, ph-metro TECNAL (Tec 3MP), segundo técnica da AOAC (2000).

\subsection{4 Ácidos orgânicos}

Foram determinados e quantificados os seguintes ácidos: ascórbico, cítrico, tartárico e málico. A extração das amostras foi realizada pela adição de aproximadamente $1 \mathrm{~g}$ de amostra triturada e $5 \mathrm{ml}$ de solução de $\mathrm{H}_{2} \mathrm{SO}_{4} 0,05$ mol.l-1, deixado em banho ultrassom por dez minutos. $\mathrm{A}$ solução resultante foi filtrada em membrana de polietileno $0,45 \mu \mathrm{m}$ (Milipore) diretamente em vial de $2,0 \mathrm{ml}$.

Um HPLC Shimadzu, equipado com bombas quaternárias de alta pressão modelo LC-20 $A D$, um detector de arranjo de diodos (DAD) modelo SPD-M20A e um injetor automático modelo SIL-M 20A foram utilizados na análise.

A separação dos componentes da amostra foi realizada empregando-se uma coluna empacotada Shim-pack VP-ODS (250 $\mathrm{mm} \times 4,6 \mathrm{~mm}$ ) conectada a uma pré-coluna Shim-pack VP-ODS $(5,0 \mathrm{~mm} \times 4,0 \mathrm{~mm})$. A fase móvel utilizada foi tampão fosfato 0,005 mol.l-1 $(\mathrm{pH}=3)$. A absorbância medida a $254 \mathrm{~nm}$ para o ácido ascórbico é $210 \mathrm{~nm}$ para os demais ácidos, no fluxo de $1,0 \mathrm{ml}$.min-1, temperatura ambiente $\left(25^{\circ} \mathrm{C}\right)$, volume de injeção de $20 \mu \mathrm{l}$ e método isocrático.

A quantificação foi realizada utilizando-se o método de padronização externa. A curva analítica foi obtida por sucessivas diluições da solução estoque em solução de tampão fosfato 0,005 mol.l-1 ( $\mathrm{pH}=3$ ). Essa quantificação foi obtida por regressão linear, plotando-se a área do pico versus concentração.

\subsubsection{Atividade respiratória}

A taxa respiratória foi determinada pelo monitoramento de gases (porcentagem de $\mathrm{O}_{2} \mathrm{e}$ $\mathrm{CO}_{2}$ ), utilizando-se PBI Dansensor, após repouso das cenouras por uma hora em frasco de vidro fechado hermeticamente.

\subsubsection{Pectina total, pectina solúvel e solubilidade}

Foram extraídas segundo a técnica descrita por McCready e McComb (1952) e determinadas colorimetricamente, segundo Bitter e Muir (1962). Os resultados foram expressos em miligramas de ácido galacturônico. $100 \mathrm{~g} \mathrm{~g}^{-1}$ de fruto. O percentual de solubilidade foi obtido pela razão entre a pectina solúvel e a pectina total (PS/PT). 


\subsubsection{Firmeza}

Determinada em texturômetro TA.XT2i, utilizando-se probe HDP/VB, sendo avaliada a força $(\mathrm{N})$ gasta para romper o tecido da amostra e penetrar $5 \mathrm{~mm}$ da rodela de cenoura.

\subsubsection{Cor}

Foi avaliada a coloração de três diferentes regiões: periférica (ao longo do perímetro da circunferência), central (no centro da circunferência) e lateral (entre a região central e a perimetral) (figura 1) em colorímetro Minolta modelo CR 400 (Japão), trabalhando com D65 (luz do dia) e usando os padrões CIE Lab, onde: L (correspondente à claridade) varia de 0 (preto) a 100 (branco), $a^{*}$ varia do -60 (verde) ao +60 (vermelho) e b* varia do -60 (azul) ao +60 (amarelo). As variáveis a* e $b^{*}$ foram utilizadas para calcular o valor do ângulo Hue $\left({ }^{\circ} \mathrm{H}\right)$ e da cromaticidade $\left(\mathrm{C}^{*}\right)$, conforme recomendado por McGuire (1992).

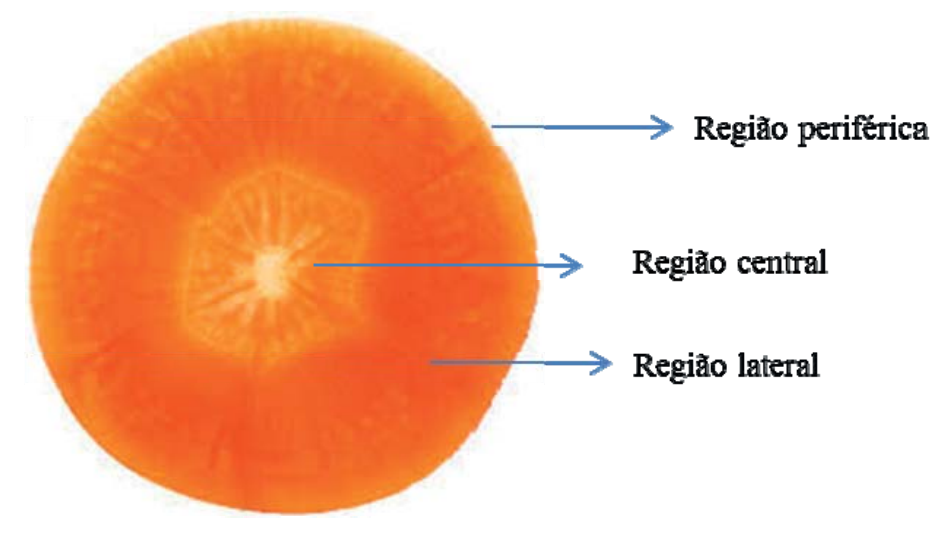

\section{FIGURA 1 - REGIÕES DA CENOURA EM QUE FOI AVALIADA A COLORAÇÃO. UFLA, LAVRAS, 2015}

\subsubsection{Atividade antioxidante total}

Para a obtenção do extrato, utilizou-se metodologia descrita por Brand-Williams, Cuvelier e Berset (1995), adaptada por Rufino et al. (2007). Utilizaram-se $2 \mathrm{~g}$ das amostras trituradas em $20 \mathrm{ml}$ de álcool metílico $50 \%$ e deixadas em repouso por uma hora à temperatura ambiente. Após esse período, a mistura foi centrifugada a 14.000 rpm por 15 minutos. O sobrenadante foi coletado e adicionaram-se $20 \mathrm{ml}$ de acetona $70 \%$ ao resíduo, que foi homogeneizado e deixado em repouso por uma hora à temperatura ambiente. Em seguida, centrifugou-se a 14.000 rpm por 15 minutos. 0 sobrenadante foi coletado, adicionado ao primeiro sobrenadante e o volume foi completado até 50 $\mathrm{ml}$ com água destilada.

A metodologia empregada na determinação da atividade antioxidante foi baseada na extinção da absorção do radical 2,2-difenil-1-picril hidrazil (DPPH $60 \mu \mathrm{m}$ ), proposta por Rufino et al. (2007), com algumas adaptações em relação ao cálculo, calculando-se o percentual de sequestro do radical livre DPPH a partir do padrão.

Para a determinação da capacidade antioxidante, foi adicionado $0,1 \mathrm{~mL}$ de cada extrato das amostras a 3,9 mL de solução de DPPH. Para o controle, foi adicionado 0,1 ml de metanol juntamente ao DPPH, no lugar do extrato. As leituras foram realizadas após 30 minutos, em espectrofotômetro a $515 \mathrm{~nm}$, e os resultados foram expressos em percentual de sequestro de radical livre (\% SRL), conforme equação 1:

$$
\% S R L=(A c-A m) \times 100 / A c
$$

em que:Ac = absorbância do controle; $\mathrm{Am}$ = absorbância da amostra 


\subsubsection{Fenólicos totais}

Para a determinação e quantificação dos compostos fenólicos totais foi utilizado o extrato, extraído para a análise de atividade antioxidante total. Os fenólicos totais foram obtidos conforme $o$ método colorimétrico, desenvolvido por Waterhouse (2002), com a utilização do reagente de FolinCiocalteu, em solução com concentração de $10 \%$ (v/v).

Para calcular os teores de fenólicos totais, construiu-se uma curva-padrão com solução de ácido gálico. Os resultados foram expressos como equivalentes de ácido gálico ( $\mathrm{g} \mathrm{EAG.g}{ }^{-1} \mathrm{de}$ cenoura).

\subsection{ANÁLISES MICROBIOLÓGICAS}

As análises foram realizadas no Laboratório de Microbiologia do Departamento de Ciência dos Alimentos da UFLA. Todas as análises foram feitas em triplicata utilizando três diluições $\left(10^{-1}\right.$, $\left.10^{-2}, 10^{-3}\right)$. A unidade analítica para as análises de coliformes a $35^{\circ} \mathrm{C}$ e $45^{\circ} \mathrm{C}$ e fungos filamentosos e leveduras das cenouras foram $25 \mathrm{~g}$ retirados assepticamente da amostra e transferidos para um agitador estéril com $225 \mathrm{ml}$ de água peptonada $0,1 \%$, utilizada para fazer as diluições decimais seriadas subsequentes. Essas diluições foram preparadas em tubos contendo $9 \mathrm{ml}$ de água peptonada $0,1 \%$, utilizando-se a técnica de transferência de $1 \mathrm{ml}$ da amostra.

As metodologias utilizadas foram as propostas pela International Commission on Microbiological Specifications for Foods - ICMSF e por Silva et al. (2007).

\subsubsection{Coliformes a $35^{\circ} \mathrm{C}$ e $45^{\circ} \mathrm{C}$ (termotolerantes)}

Foi utilizado o método de determinação em tubos contendo Caldo Lauril Sulfato Triptose (LST) a $35{ }^{\circ} \mathrm{C}$ para contagem de coliformes totais e a $45{ }^{\circ} \mathrm{C}$ para contagem de coliformes termotolerantes. A presença de Escherichia coli foi confirmada com a inoculação de alíquotas dos tubos positivos para coliformes a $45^{\circ} \mathrm{C}$ em placas contendo ágar eosina azul de metileno (EMB). Foram consideradas positivas as colônias típicas com coloração verde brilhante.

\subsubsection{Determinação de Salmonella sp.}

Foram pesados $25 \mathrm{~g}$ de amostra, adicionados a erlenmeyers contendo $225 \mathrm{ml}$ de água tamponada e incubados, a $37^{\circ} \mathrm{C}$, por 18 horas. Posteriormente, realizou-se o enriquecimento da amostra utilizando-se os caldos tetrationato e rapaport, com incubação, a $37^{\circ} \mathrm{C}$, por 24 horas. Para o plaqueamento, foi utilizado o meio Rambach, incubado a $37{ }^{\circ} \mathrm{C}$, por 24 horas. Colônias suspeitas foram isoladas e transferidas para tubos contendo ágar ferro tríplice açúcar (TSI) e ágar lisina de ferro (LIA), sendo incubados, a $37^{\circ} \mathrm{C}$, por 24 horas e, posteriormente, submetidos a provas bioquímicas.

\subsubsection{Contagem de fungos filamentosos e leveduras}

Para a contagem de fungos filamentosos e leveduras foi utilizado método de contagem por plaqueamento em superfície com meio de cultura ágar dicloran rosa de bengala cloranfenicol (DRBC).

\subsection{ANÁLISE ESTATÍSTICA}

Os dados foram submetidos à análise de variância e, quando os fatores isolados ou sua interação foram significativos, à regressão polinomial e ao teste de Tukey, a $5 \%$ de significância, usando delineamento inteiramente casualizado (DIC) em fatorial 4x5 (quatro tratamentos e cinco tempos de armazenamento), com três repetições, sendo a parcela experimental composta por uma bandeja (aproximadamente $100 \mathrm{~g}$ ) de cenouras minimamente processadas, utilizando software SISVAR (versão 5.3) (FERREIRA, 1999). Quando houve efeito significativo da interação, realizouse o desdobramento das doses em cada tempo de armazenamento. 


\section{RESULTADOS E DISCUSSÃO}

\subsection{PERDA DE MASSA}

Houve efeito significativo da interação tempo $x$ tratamento $(p<0,05)$ para a variável perda de massa de cenouras minimamente processadas. A perda de massa foi crescente, independentemente do tratamento utilizado. Entretanto, cenouras submetidas à cobertura comestível (T1, T2 e C1) apresentaram menor perda de massa no decorrer do tempo (figura 2). Cenouras recobertas com cobertura comestível de amido + MNFC de cenoura ( $\mathrm{T} 1$ e T2) sofreram menor perda de massa ao fim do armazenamento (figura 2), sugerindo que as micro/nanofibrilas são capazes de melhorar as propriedades das coberturas e filmes biodegradáveis, como a propriedade de barreira à perda de água (AZEREDO et al., 2009; AZEREDO et al., 2012).

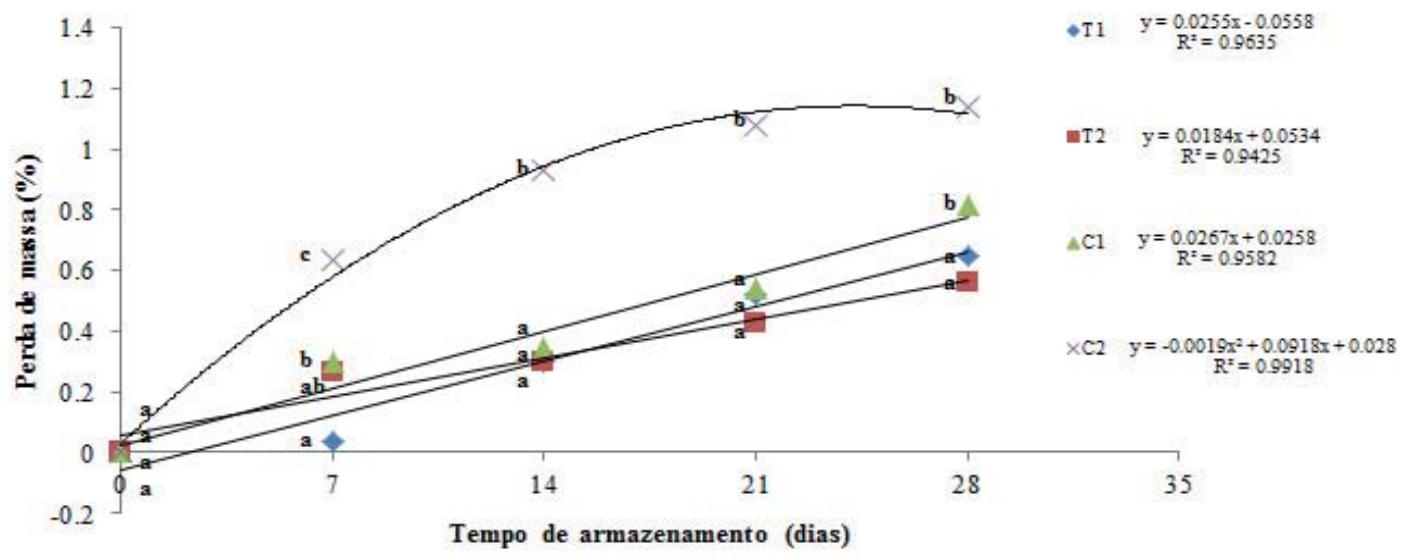

\section{FIGURA 2 - PERDA DE MASSA DURANTE O ARMAZENAMENTO REFRIGERADO DE CENOURAS MINIMAMENTE PROCESSADAS COM DIFERENTES TRATAMENTOS}

(T1: cenouras recobertas com cobertura comestível de amido + micro/nanofibrilas de cenoura a 20\%; T2: cenouras recobertas com cobertura comestível de amido + micro/nanofibrilas de cenoura a 40\%; C1: cenouras recobertas com cobertura comestível de amido sem micro/nanofibrilas de cenoura; $\mathrm{C} 2$ : cenouras sem qualquer recobrimento). As médias seguidas pela mesma letra em cada tempo de armazenamento não se diferem entre si, pelo teste de Tukey, a $5 \%$ de significância. UFLA, Lavras, 2015

A perda de massa excessiva é um dos principais fatores relacionados com a perda da qualidade comercial de frutos e hortaliças (MEDINA, 1984). Estes sofrem alguma perda de massa durante o armazenamento devido ao efeito combinado de respiração e transpiração, mesmo quando mantidos em condições ideais (CHITARRA; CHITARRA, 2005). Segundo Vicentini et al. (1999), a perda de pequenas quantidades de água por frutas e hortaliças é tolerável, mas aquelas que resultam em murchamento, ou enrugamento, devem ser controladas. O murchamento pode ser minimizado pela redução da taxa de transpiração, que pode ser diminuída pelo aumento da umidade relativa e pela diminuição da temperatura ambiente (BARROS et al., 1994). Outras maneiras de amenizar a perda de massa são a utilização de atmosfera modificada e/ou o recobrimento com filmes comestíveis, juntamente com o emprego da refrigeração (LANA, 2000), bem como a utilização de coberturas de nanobiocompósitos.

Segundo Izume et al. (1996), a perda de matéria fresca por cenoura minimamente processada é o somatório da perda de água por transpiração e da perda de carbono pela respiração, processo que ocorre durante todo o período de armazenamento, sendo tanto maior quanto maior for a temperatura e quanto menor for o tamanho dos cortes. Pelos resultados do presente trabalho, fica claro que o recobrimento das cenouras minimamente processadas com 
cobertura comestível de amido e reforçadas com MNFC de cenoura diminui a perda de massa provavelmente devido à diminuição da transpiração e da respiração, já que o recobrimento tem propriedades de barreira ao vapor d'água e a gases, e as micro/nanofibrilas melhoram ainda mais essas propriedades.

\subsection{SÓLIDOS SOLÚVEIS (SS), AÇÚCARES SOLÚVEIS TOTAIS (AST)}

Houve efeito significativo da interação tratamento $x$ tempo para SS e para AST. Não foi possível ajustar a regressão para essas variáveis, pois $\circ \mathrm{R}^{2}$ calculado apresentou valor insatisfatório (abaixo de 60\%). Os SS variaram de 6\% a 9\%, sendo observado um leve aumento em todos os tratamentos no decorrer do armazenamento. No $21^{\circ}$ dia de armazenamento, os tratamentos $\mathrm{C} 1$ e C2 apresentaram maior teor de SS. Já no último dia de armazenamento, os valores dessa variável se igualaram entre os tratamentos (tabela 1). Para AST foi observado, para todos os tratamentos, decréscimo dessa variável durante o armazenamento. Observa-se que o tratamento C2 apresenta variação dos AST no decorrer do tempo de armazenamento (tabela 2). Sabe-se que SS são representados principalmente por açúcares, mas outros compostos, como vitaminas, ácidos, pectinas e aminoácidos, em menor quantidade, também compõem essa variável, o que pode ser uma explicação para a diminuição dos AST enquanto o teor de SS aumentou discretamente.

De acordo com Chitarra e Carvalho (1984), a cenoura é constituída essencialmente por açúcares livres, com predominância da sacarose sobre a glicose e a frutose, o que lhe proporciona grande sensibilidade gustativa, e Carlin et al. (1990) afirmam que, em resposta à injúria causada em cenouras minimamente processadas, algumas alterações ocorrem, e entre elas citam a diminuição de sacarose, glicose e frutose. Assim, a diminuição observada nos AST no presente trabalho pode ser um efeito causado pelo processamento mínimo.

\section{TABELA 1 - VALORES MÉDIOS DE SS (\%) DE CENOURAS MINIMAMENTE PROCESSADAS DE DIFERENTES TRATAMENTOS E ARMAZENADAS POR 28 DIAS}

SS (\%)

Tempo de armazenamento (dias)

\begin{tabular}{ccccc} 
& T1 & T2 & C1 & C2 \\
\hline 0 & $6.44 \mathrm{a}$ & $6.44 \mathrm{a}$ & $6.44 \mathrm{a}$ & $6.44 \mathrm{a}$ \\
\hline 7 & $6.99 \mathrm{ab}$ & $8.00 \mathrm{~b}$ & $6.67 \mathrm{a}$ & $7.33 \mathrm{ab}$ \\
\hline 14 & $7.44 \mathrm{a}$ & $7.89 \mathrm{ab}$ & $9.67 \mathrm{c}$ & $8.67 \mathrm{bc}$ \\
\hline 21 & $6.67 \mathrm{a}$ & $7.67 \mathrm{ab}$ & $8.33 \mathrm{~b}$ & $8.33 \mathrm{~b}$ \\
\hline 28 & $7.67 \mathrm{a}$ & $7.89 \mathrm{a}$ & $7.89 \mathrm{a}$ & $7.89 \mathrm{a}$ \\
\hline
\end{tabular}

Médias seguidas de letras iguais em cada tempo não diferem entre si, a $5 \%$ de probabilidade, pelo teste de Tukey. T1: cenouras recobertas com cobertura comestível de amido + micro/nanofibrilas de cenoura a 20\%; T2: cenouras recobertas com cobertura comestível de amido + micro/nanofibrilas de cenoura a 40\%; C1: cenouras recobertas com cobertura comestível de amido sem micro/nanofibrilas de cenoura; $\mathrm{C} 2$ : cenouras sem qualquer recobrimento 


\section{TABELA 2 - VALORES MÉDIOS DE AÇÚCARES SOLÚVEIS TOTAIS (G.100G-1) DE CENOURAS MINIMAMENTE PROCESSADAS DE DIFERENTES TRATAMENTOS ARMAZENADAS POR 28 DIAS}

\begin{tabular}{|c|c|c|c|c|}
\hline \multirow{2}{*}{ Tempo de armazenamento (dias) } & \multicolumn{4}{|c|}{ AST $\left(\mathrm{g} .100 \mathrm{~g}^{-1}\right)$} \\
\hline & $\mathrm{T} 1$ & $\mathrm{~T} 2$ & $\mathrm{C} 1$ & $\mathrm{C} 2$ \\
\hline 0 & $5.096 \mathrm{a}$ & $5.096 \mathrm{a}$ & $5.096 \mathrm{a}$ & $5.096 \mathrm{a}$ \\
\hline 7 & $5.817 b$ & $7.590 \mathrm{c}$ & $2.993 \mathrm{a}$ & $3.177 \mathrm{a}$ \\
\hline 14 & $4.437 \mathrm{a}$ & $4.080 \mathrm{a}$ & $4.223 \mathrm{a}$ & $3.593 \mathrm{a}$ \\
\hline 21 & $4.157 \mathrm{a}$ & $3.527 \mathrm{a}$ & $5.923 \mathrm{~b}$ & $3.960 \mathrm{a}$ \\
\hline 28 & $3.810 \mathrm{a}$ & $3.530 \mathrm{a}$ & $4.027 \mathrm{a}$ & $3.903 \mathrm{a}$ \\
\hline
\end{tabular}

Médias seguidas de letras iguais em cada tempo não diferem entre si, a $5 \%$ de probabilidade, pelo teste de Tukey. T1: cenouras recobertas com cobertura comestível de amido + micro/nanofibrilas de cenoura a 20\%; T2: cenouras recobertas com cobertura comestível de amido + micro/nanofibrilas de cenoura a 40\%; C1: cenouras recobertas com cobertura comestível de amido sem micro/nanofibrilas de cenoura; C2: cenouras sem qualquer recobrimento

\subsection{PH, ACIDEZ TOTAL (AT) E ÁCIDOS ORGÂNICOS}

Houve efeito significativo apenas do tempo de armazenamento, independentemente do tipo de tratamento, sobre as variáveis pH e AT. Segundo Chitarra e Chitarra (2005), o pH aumenta com a diminuição da acidez, exatamente o que se observa no presente trabalho: discreto aumento do $\mathrm{pH}$, acompanhado de discreta diminuição da AT ao longo do armazenamento (figura 3). $\mathrm{O} \mathrm{pH}$ variou de 6,1 a 6,45 (figura $3 A$ ) e a AT variou de $0,08 \%$ a $0,063 \%$ de ácido málico (figura 3B). Resultado semelhante foi observado por Pilon (2003) e Alves et al. (2010) em cenouras minimamente processadas armazenadas sob refrigeração por 21 e 8 dias respectivamente.

Os ácidos málico, ascórbico, cítrico, isocítrico e succínico foram identificados e quantificados nos diferentes tratamentos de cenouras minimamente processadas ao longo do tempo de armazenamento. Não houve efeito significativo de nenhum dos fatores para o ácido ascórbico, que apresentou valores próximos a 0,025 mg. ${ }^{-1}$. Já para os demais ácidos encontrados, houve efeito significativo da interação tratamento $x$ tempo de armazenamento. Não foi possível ajustar a regressão para os ácidos cítrico, isocítrico e succínico, pois o $R^{2}$ calculado apresentou valor insatisfatório (abaixo de 60\%).

Observa-se diminuição da quantidade de ácido málico, ácido orgânico majoritário em cenoura, ao longo do armazenamento em todos os tratamentos, sendo que T2 apresentou maior quantidade desse ácido no último dia de armazenamento (figura 4). O processamento mínimo leva ao aumento do processo respiratório dos vegetais e, segundo Brody (1996), o teor de ácidos orgânicos tende a diminuir, levando ao aumento do $\mathrm{pH}$ durante o processo de oxidação dos ácidos no ciclo dos ácidos tricarboxílicos, em decorrência do processo de respiração, o que explica a diminuição do teor do ácido málico durante o armazenamento das cenouras minimamente processadas.

Em relação ao ácido cítrico, observou-se diferença entre os tratamentos apenas aos 14 e aos 21 dias de armazenamento, sendo que o tratamento T1 apresentou maior valor nesses dois tempos (tabela 3). Os resultados encontrados para os ácidos málico e cítrico sugerem que o uso de cobertura de amido reforçada com MNFC de cenoura contribuiu para menor perda desses ácidos em cenouras minimamente processadas armazenadas por 28 dias sob refrigeração. 
Para os ácidos isocítrico e succínico, observou-se discreto aumento ao longo do armazenamento em todos os tratamentos, sendo que, ao final do armazenamento, o tratamento C1 apresentou o maior valor para o ácido isocítrico (tabela 4) e o tratamento C2 apresentou maior valor para o ácido succínico (tabela 5). Babic et al. (1993) comentam que o aumento de ácidos em cenouras minimamente processadas pode estar relacionado com o processo de lignificação e suberização e também com o mecanismo de defesa contra microrganismos.

A acidez em produtos hortícolas é atribuída, principalmente, aos ácidos orgânicos que se encontram dissolvidos nos vacúolos das células, tanto na forma livre como na combinada com sais, ésteres, glicosídeos, etc. (CHITARRA; CHITARRA, 2005). Os ácidos orgânicos influenciam fortemente as propriedades sensoriais de vegetais em geral, principalmente no que diz respeito a sabor, cor e aroma (KADER, 2008). Além disso, ácidos orgânicos afetam indiretamente o metabolismo de fenólicos por alteração do $\mathrm{pH}$ e por agirem como precursores destes (GALDON et al., 2008; KADER, 2008), o que pode justificar a diminuição da AT e de alguns ácidos orgânicos, como o málico e o cítrico, concomitantemente ao aumento no conteúdo de fenólicos totais (dados discutidos adiante).

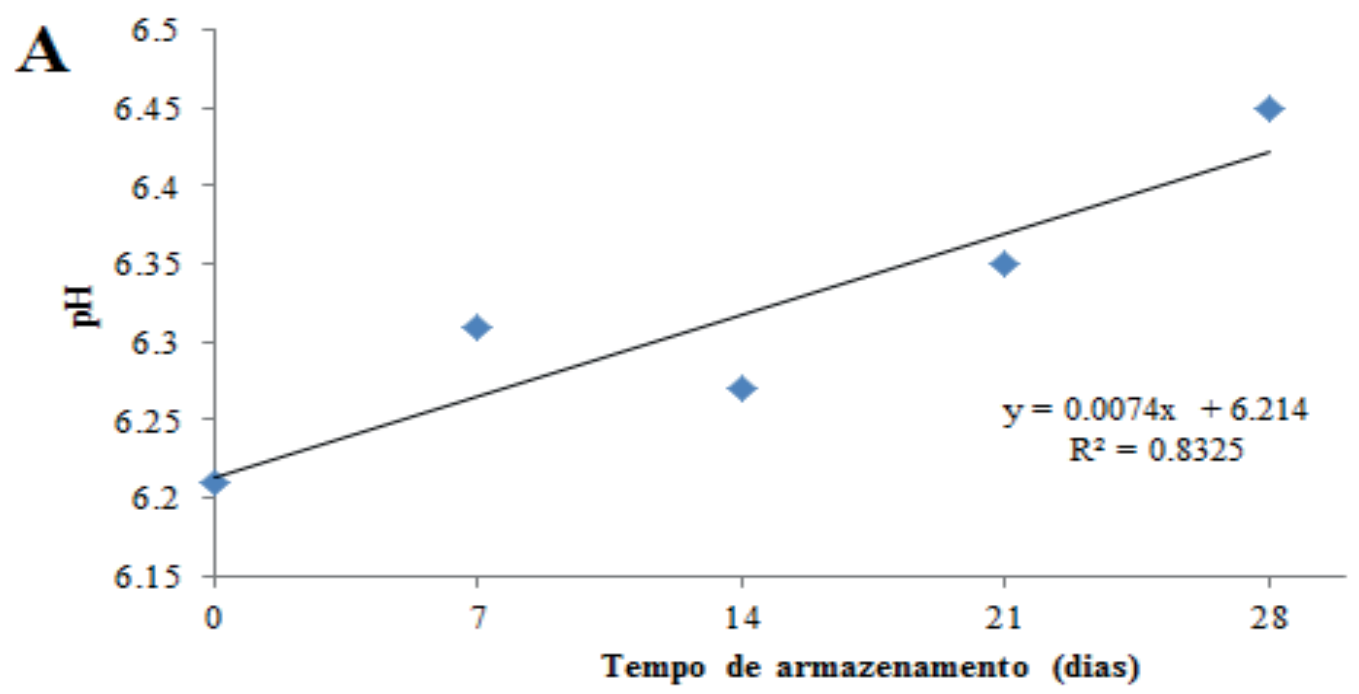

B

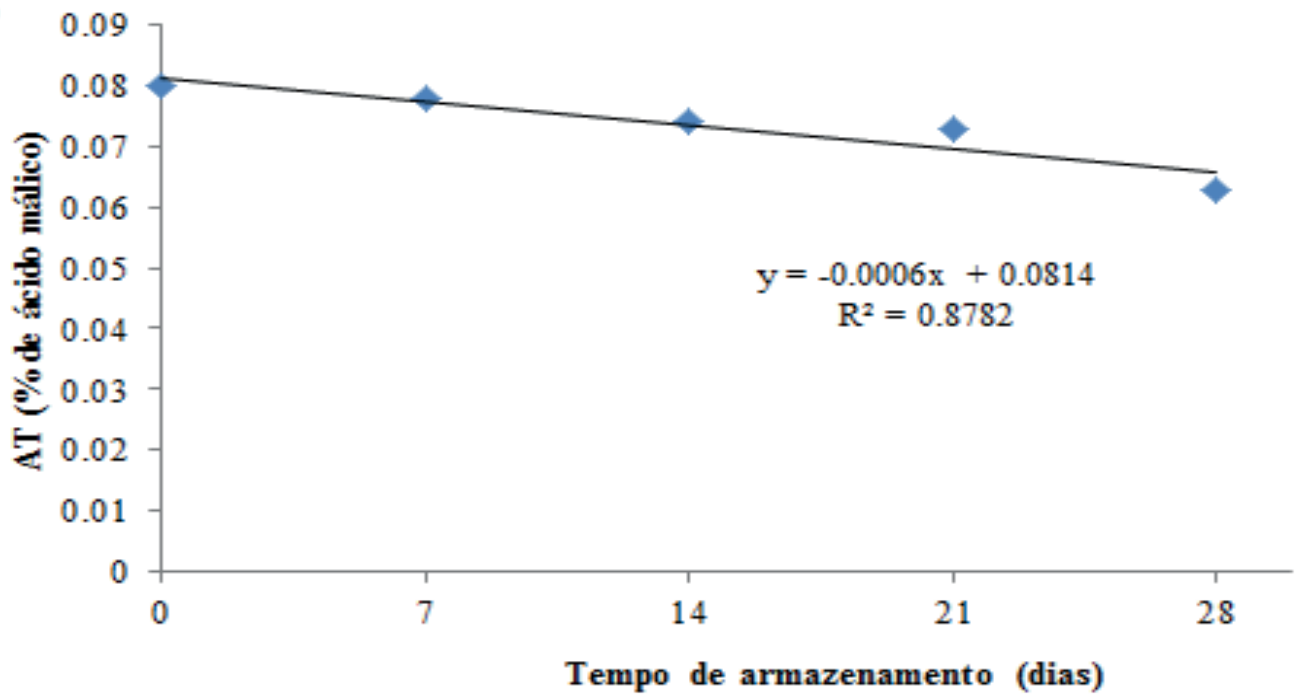




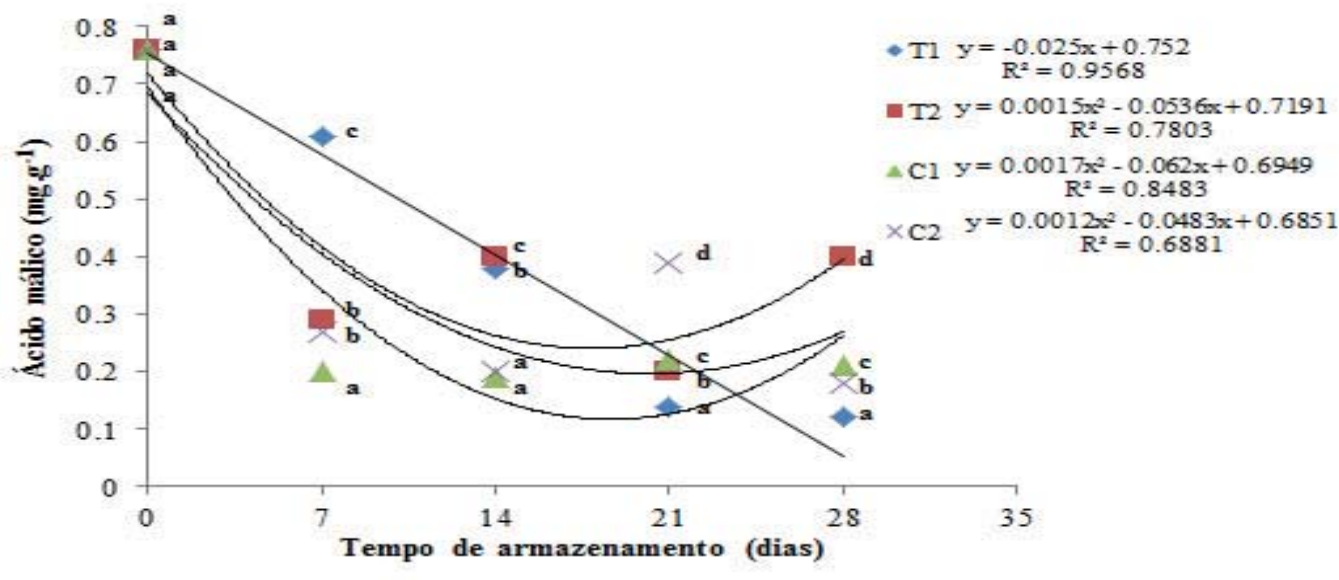

FIGURA 4 - TEOR DE ÁCIDO MÁLICO DURANTE O ARMAZENAMENTO REFRIGERADO DE CENOURAS MINIMAMENTE PROCESSADAS COM DIFERENTES TRATAMENTOS

(T1: cenouras recobertas com cobertura comestível de amido + micro/nanofibrilas de cenoura a 20\%; T2: cenouras recobertas com cobertura comestível de amido + micro/nanofibrilas de cenoura a $40 \%$; C1: cenouras recobertas com cobertura comestível de amido sem micro/nanofibrilas de cenoura; C2: cenouras sem qualquer recobrimento). As médias seguidas pela mesma letra em cada tempo de armazenamento não diferem entre si, pelo teste de Tukey, a 5\% de significância. UFLA, Lavras, 2015

\section{TABELA 3 - VALORES MÉDIOS DE ÁCIDO CÍTRICO (MG.G-1) DE CENOURAS MINIMAMENTE PROCESSADAS DE DIFERENTES TRATAMENTOS E ARMAZENADAS POR 28 DIAS}

\begin{tabular}{|c|c|c|c|c|}
\hline \multirow{2}{*}{ Tempo de armazenamento (dias) } & \multicolumn{4}{|c|}{ Ácido cítrico $\left(\mathrm{mg} \cdot \mathrm{g}^{-1}\right)$} \\
\hline & $\mathrm{T} 1$ & $\mathrm{~T} 2$ & $\mathrm{C} 1$ & $\mathrm{C} 2$ \\
\hline 0 & $0.015 a$ & $0.015 a$ & $0.015 a$ & $0.015 a$ \\
\hline 7 & $0.015 \mathrm{a}$ & $0.022 \mathrm{a}$ & $0.01 \mathrm{a}$ & $0.01 \mathrm{a}$ \\
\hline 14 & $0.083 b$ & $0.029 a$ & $0.01 \mathrm{a}$ & $0.01 \mathrm{a}$ \\
\hline 21 & $0.040 \mathrm{~b}$ & $0.03 a b$ & $0.007 \mathrm{a}$ & $0.003 a b$ \\
\hline 28 & $0.01 \mathrm{a}$ & $0.023 a$ & $0.01 \mathrm{a}$ & $0.02 \mathrm{a}$ \\
\hline
\end{tabular}

Médias seguidas de letras iguais em cada tempo não diferem entre si, a 5\% de probabilidade, pelo teste de Tukey. T1: cenouras recobertas com cobertura comestível de amido + micro/nanofibrilas de cenoura a 20\%; T2: cenouras recobertas com cobertura comestível de amido + micro/nanofibrilas de cenoura a 40\%; C1: cenouras recobertas com cobertura comestível de amido sem micro/nanofibrilas de cenoura; $\mathrm{C} 2$ : cenouras sem qualquer recobrimento 


\section{TABELA 4 - VALORES MÉDIOS DE ÁCIDO ISOCÍTRICO (MG.G-1) DE CENOURAS MINIMAMENTE PROCESSADAS DE DIFERENTES TRATAMENTOS \\ E ARMAZENADAS POR 28 DIAS}

\section{Tempo de armazenamento (dias)}

\section{0}

7

14

21

28

$\begin{array}{lc} & \mathrm{T} 1 \\ 0 & 0.04 \mathrm{a} \\ 7 & 0.06 \mathrm{~b} \\ & 0.034 \mathrm{a} \\ & \\ 21 & 0.073 \mathrm{a} \\ & \\ & 0.07 \mathrm{~b}\end{array}$

$0.07 \mathrm{~b}$

\section{Ácido isocítrico (mg.g-1)}

T2

C1

C2

$\begin{array}{llll}04 a & 0.04 a & 0.04 a & 0.04 a\end{array}$

$\begin{array}{llll}06 \mathrm{~b} & 0.05 \mathrm{a} & 0.08 \mathrm{c} & 0.18 \mathrm{~d}\end{array}$

0.034 a

$0.058 b$

$0.088 c$

$0.11 d$

0.073 a

0.039 a

$0.41 \mathrm{c}$

$0.15 b$

0.049 a

$0.13 c$

$0.07 \mathrm{~b}$

Médias seguidas de letras iguais em cada tempo não diferem entre si, a $5 \%$ de probabilidade, pelo teste de Tukey. T1: cenouras recobertas com cobertura comestível de amido + micro/nanofibrilas de cenoura a 20\%; T2: cenouras recobertas com cobertura comestível de amido + micro/nanofibrilas de cenoura a 40\%; C1: cenouras recobertas com cobertura comestível de amido sem micro/nanofibrilas de cenoura; C2: cenouras sem qualquer recobrimento

\section{TABELA 5 - VALORES MÉDIOS DE ÁCIDO SUCCÍNICO (MG.G-1) DE CENOURAS MINIMAMENTE PROCESSADAS DE DIFERENTES TRATAMENTOS E ARMAZENADAS POR 28 DIAS}

\begin{tabular}{ccccc}
\hline & \multicolumn{4}{c}{ Ácido succínico (mg.g-1) } \\
Tempo de armazenamento (dias) & T1 & T2 & C1 & $0.11 \mathrm{a}$ \\
\cline { 2 - 5 } 0 & $0.11 \mathrm{a}$ & $0.11 \mathrm{a}$ & $0.11 \mathrm{a}$ & $0.088 \mathrm{~b}$ \\
\hline 7 & $0.024 \mathrm{a}$ & $0.082 \mathrm{~b}$ & $0.07 \mathrm{~b}$ & $0.089 \mathrm{~b}$ \\
\hline 14 & $0.012 \mathrm{a}$ & $0.082 \mathrm{~b}$ & $0.088 \mathrm{~b}$ & $0.01 \mathrm{a}$ \\
\hline 21 & $0.077 \mathrm{a}$ & $0.087 \mathrm{a}$ & $0.077 \mathrm{a}$ & $0.09 \mathrm{~b}$ \\
\hline
\end{tabular}

Médias seguidas de letras iguais em cada tempo não diferem entre si, a 5\% de probabilidade, pelo teste de Tukey. T1: cenouras recobertas com cobertura comestível de amido + micro/nanofibrilas de cenoura a 20\%; T2: cenouras recobertas com cobertura comestível de amido + micro/nanofibrilas de cenoura a 40\%; C1: cenouras recobertas com cobertura comestível de amido sem micro/nanofibrilas de cenoura; C2: cenouras sem qualquer recobrimento

\subsection{FIRMEZA, PECTINA TOTAL (PT) E PECTINA SOLÚVEL (PS)}

A firmeza das cenouras minimamente processadas foi afetada significativamente apenas pelo tempo de armazenamento, sendo que foi observada diminuição dessa firmeza ao longo do 
tempo, independentemente do tratamento. Houve queda na firmeza das cenouras, de 82,12 $\mathrm{N}$ para $73,12 \mathrm{~N}$ (figura 5).

Pectina solúvel (PS) foi afetada significativamente pela interação tratamento $x$ tempo. Já a pectina total (PT) foi afetada pelo tempo de armazenamento e pelo tratamento, separadamente. Observase um aumento de PS até o $21^{\circ}$ dia de armazenamento em todos os tratamentos (figura 6), sendo que menor variação dessa variável foi observada no tratamento T2 ao longo do armazenamento. Para PT foi observada queda ao longo do armazenamento e que o tratamento $\mathrm{C} 2$ apresentou o maior valor médio dessa variável (figura 7). As únicas diferenças observadas em PT foram entre os tratamentos T1 e C2, apresentando-se valores médios de 1.606,53 mg.100g-1 e 1.827,94 mg.100g-1 respectivamente.

A diminuição da firmeza está relacionada, entre outros fatores, com o aumento no conteúdo de pectinas solúveis, como observado no presente trabalho.

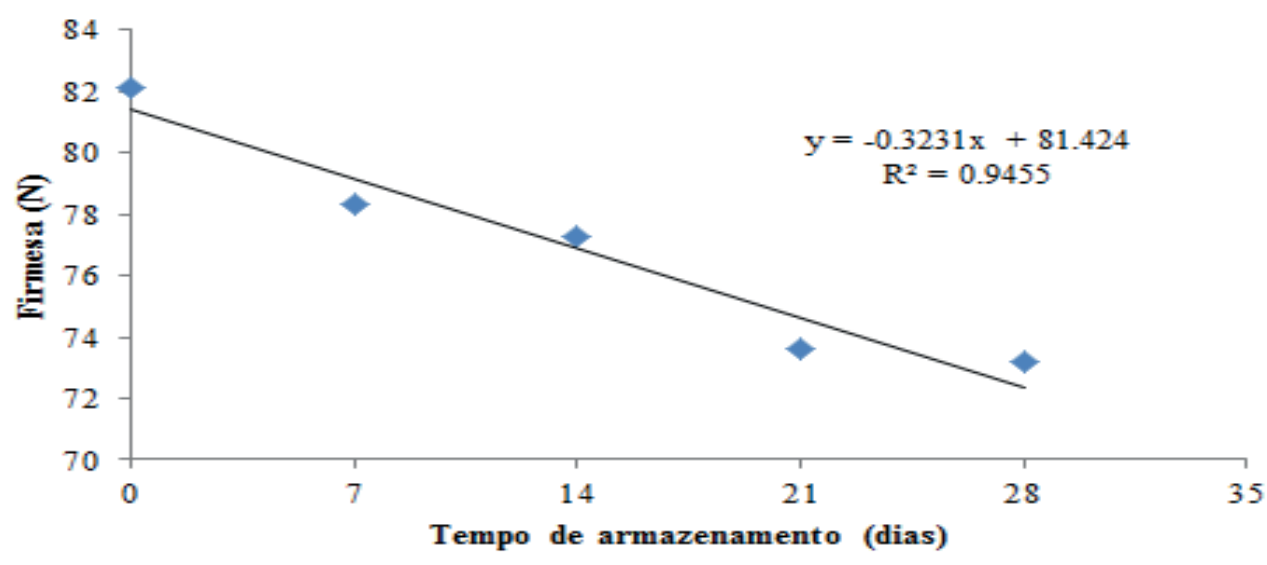

\section{FIGURA 5 - VALORES MÉDIOS DE FIRMEZA (N) DE CENOURAS MINIMAMENTE PROCESSADAS E ARMAZENADAS POR 28 DIAS. UFLA, LAVRAS, 2015.}
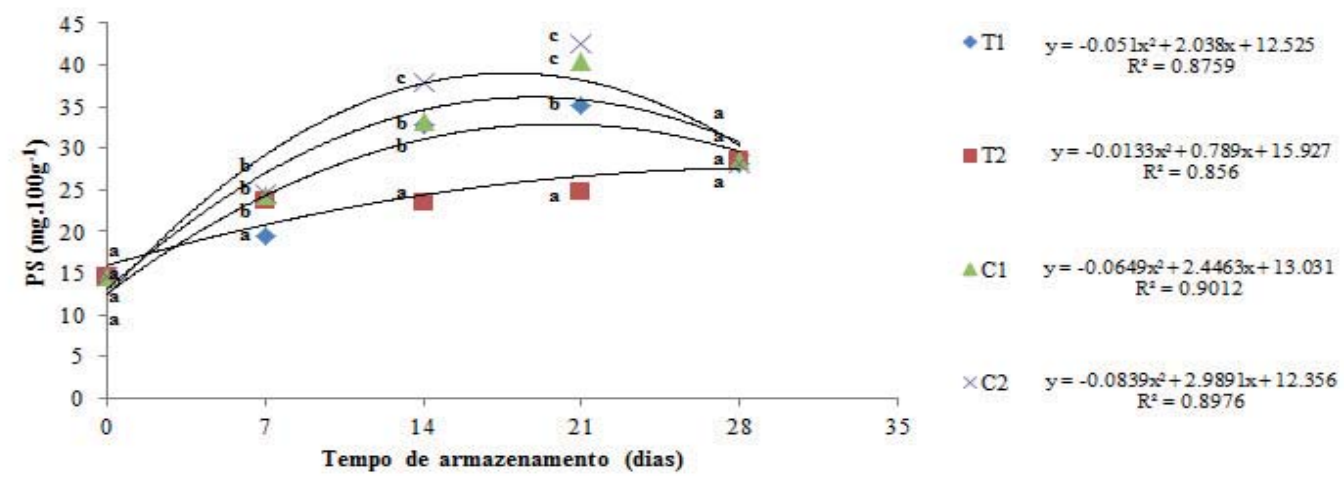

\section{FIGURA 6 - VALORES MÉDIOS DE PECTINA SOLÚVEL DURANTE O ARMAZENAMENTO REFRIGERADO DE CENOURAS MINIMAMENTE PROCESSADAS COM DIFERENTES TRATAMENTOS}

(T1: cenouras recobertas com cobertura comestível de amido + MNFC de cenoura a 20\%; T2: cenouras recobertas com cobertura comestivel de amido + MNFC de cenoura a 40\%; C1: cenouras recobertas com cobertura comestível de amido sem MNFC de cenoura; C2: cenouras sem qualquer recobrimento). As médias seguidas pela mesma letra em cada tempo de armazenamento não diferem entre si, pelo teste de Tukey, a 5\% de significância. UFLA, Lavras, 2015 


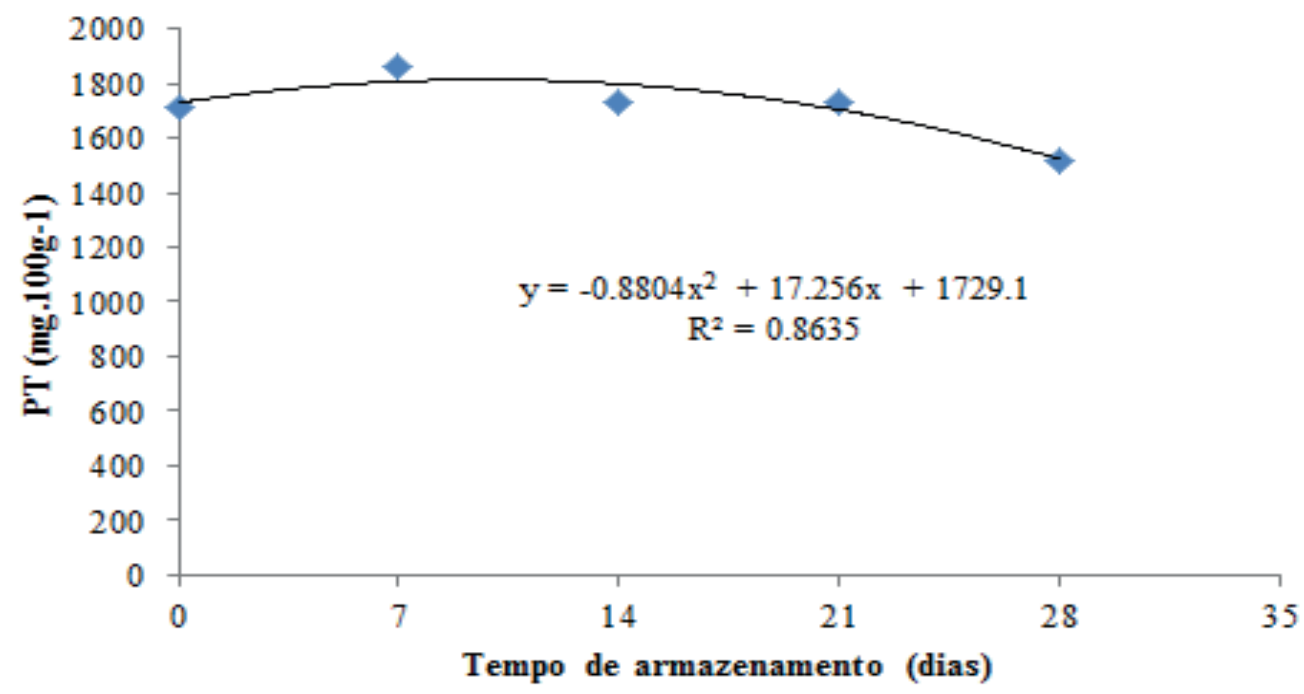

FIGURA 7 - VALORES MÉDIOS DE PECTINA TOTAL (MG.100G-1) DE CENOURAS MINIMAMENTE PROCESSADAS E ARMAZENADAS POR 28 DIAS. UFLA, LAVRAS, 2015

A firmeza de um vegetal está associada, em geral, à solubilidade das substâncias pécticas. Segundo Chitarra e Chitarra (2005), o processo de solubilização das pectinas contribui para o amaciamento dos tecidos em decorrência da redução da força de coesão entre as células, e a firmeza está relacionada com a força necessária para que o produto atinja uma dada deformação, dando uma ideia das transformações na estrutura celular, da coesão das células e das alterações bioquímicas, ocorridas durante a vida útil do produto em consequência da perda de turgor celular e/ ou da ação de enzimas hidrolíticas da parede celular.

Cybulsca et al. (2015) observaram aumento de pectinas solúveis e diminuição de pectina insolúvel em cenouras armazenadas por três meses, bem como, também, aumento das enzimas responsáveis pela degradação de pectinas: pectinametilesterase (PME), que é responsável pela desmetoxilação da pectina, e poligalactoronase (PG), que é responsável pela quebra de ligações $\alpha-(1-4)$ de ácidos poligalacturônicos. A queda observada na firmeza das cenouras minimamente processadas, além da ação de enzimas pectinolíticas, também pode ser decorrente do aumento na atividade de outras enzimas, como as enzimas glicolíticas (glucanases) que participam da hidrólise da hemicelulose e outros componentes de parede celular que estão presentes em cenouras e podem ser ativados como mecanismo de defesa a um ataque microbiológico e/ou ferimento (como o processamento mínimo, por exemplo) (TAIZ; ZEIGER, 2009; KUROSAKI et al., 1991; KUROSAKI et al., 1992), além da perda de massa, que é devido ao somatório da perda de água por transpiração e da perda de carbono através da respiração, levando ao murchamento e à consequente perda de firmeza (IZUME et al., 1996; RESENDE et al., 2004).

Assim, a queda de firmeza observada no armazenamento de cenouras minimamente processadas do presente trabalho provavelmente é devido, em maior parte, à perda de massa e ao aumento do conteúdo de pectina solúvel observados ao longo do tempo de armazenamento.

\subsection{TAXA RESPIRATÓRIA}

A taxa respiratória foi afetada significativamente pela interação tratamento $\mathrm{x}$ tempo de armazenamento. Não foi possível ajustar a regressão para essa variável, pois $\circ R^{2}$ calculado apresentou valor insatisfatório (abaixo de 60\%). Observou-se menor taxa respiratória nos tratamentos com cobertura de amido em que se adicionou MNFC de cenoura (T1 e T2), seguidos do tratamento com cobertura de amido sem adição de micro/nanofibrilas (C1), sendo que as mais altas taxas respiratórias foram observadas nas cenouras sem recobrimento algum (C2) (tabela 6). 


\section{TABELA 6 - VALORES MÉDIOS DE TAXA RESPIRATÓRIA (ML DE CO ${ }_{2} \cdot \mathrm{KG}^{-1} \cdot \mathrm{H}^{-1}$ ) DE CENOURAS MINIMAMENTE PROCESSADAS DE DIFERENTES TRATAMENTOS E ARMAZENADAS POR 28 DIAS}

\section{Tempo de armazenamento \\ (dias)}

\begin{tabular}{ccccc}
\cline { 2 - 4 } (dias) & T1 & T2 & C1 & C2 \\
\hline 0 & $17.00 \mathrm{a}$ & $16.90 \mathrm{a}$ & $16.92 \mathrm{a}$ & $17.02 \mathrm{a}$ \\
\hline 7 & $11.77 \mathrm{a}$ & $13.00 \mathrm{a}$ & $36.45 \mathrm{~b}$ & $53.67 \mathrm{c}$ \\
\hline 14 & $11.77 \mathrm{a}$ & $15.60 \mathrm{a}$ & $20.83 \mathrm{~b}$ & $32.25 \mathrm{~b}$ \\
\hline 21 & $17.00 \mathrm{a}$ & $22.10 \mathrm{~b}$ & $26.04 \mathrm{bc}$ & $30.12 \mathrm{c}$ \\
\hline 28 & $17.00 \mathrm{a}$ & $20.80 \mathrm{ab}$ & $22.13 \mathrm{bc}$ & $26.18 \mathrm{c}$ \\
\hline
\end{tabular}

Médias seguidas de letras iguais em cada tempo não diferem entre si, a $5 \%$ de probabilidade, pelo teste de Tukey. T1: cenouras recobertas com cobertura comestível de amido + micro/nanofibrilas de cenoura a 20\%; T2: cenouras recobertas com cobertura comestível de amido + micro/nanofibrilas de cenoura a 40\%; C1: cenouras recobertas com cobertura comestível de amido sem micro/nanofibrilas de cenoura; $\mathrm{C} 2$ : cenouras sem qualquer recobrimento

Os danos físicos causados durante o processamento mínimo podem ocasionar o aumento de produção de etileno e da taxa respiratória (KATO-NOGUSHI \& WATADA, 1997). A taxa respiratória de cenouras minimamente processadas pode ser o dobro da taxa respiratória de cenouras inteiras e chegar a ser quatro ou cinco vezes maior após algumas horas do processamento, dependendo do tipo de corte (CHERVIN et al., 1992; IZUMI et al., 1996). Como consequência, ocorre a aceleração de complexas reações bioquímicas responsáveis pelas alterações de cor, como o esbranquiçamento, e pelas perdas de aroma, sabor e qualidade nutricional (HUXSOLL \& BOLIN, 1989). A elevação da taxa respiratória de cenouras minimamente processadas, bem como o consequente aumento de reações bioquímicas, é tanto maior quanto maior for a temperatura de armazenamento, sendo ideal manter as cenouras sob temperaturas de refrigeração de aproximadamente $5{ }^{\circ} \mathrm{C}$, assegurando baixa taxa respiratória e metabolismo menos ativo (SAPGNOL et al., 2006).

O controle do efeito dos ferimentos sobre o metabolismo do produto é a chave para manter a qualidade de um produto minimamente processado durante o período necessário para distribuição e comercialização (BRECHT, 1995). O impacto dos danos físicos sobre a taxa respiratória pode ser reduzido pelo resfriamento do produto, uso de atmosfera modificada, uso de película comestível, etc. Os efeitos da película comestível sobre a taxa respiratória, observados neste e em outros trabalhos, se devem ao controle da migração de vapor d'água e à permeabilidade ao $\mathrm{O}_{2}$ e ao $\mathrm{CO}_{2}, \mathrm{O}$ que leva à redução da taxa de respiração através da criação de uma atmosfera modificada em torno do vegetal, retardando assim a senescência (LI; BARTH, 1998; ALI et al., 2011; LAl et al., 2013).

\subsection{COLORAÇÃO}

As variáveis claridade $\left({ }^{*} \mathrm{~L}\right)$, cromaticidade $\left(\mathrm{C}^{*}\right)$ e ângulo Hue $\left({ }^{\circ} \mathrm{H}\right)$ foram avaliadas em diferentes pontos da cenoura minimamente processada (central, lateral e periférica) (figura 1).

Em relação à parte central das cenouras, houve efeito significativo da interação tratamento $x$ tempo de armazenamento para as variáveis $L^{*} e C^{*}$, sendo que a variável ${ }^{\circ} \mathrm{H}$ variou significativamente somente em função do tempo de armazenamento; na parte lateral, as três variáveis analisadas ( $L^{*}$, 
$\mathrm{C}^{*} \mathrm{e}{ }^{\circ} \mathrm{H}$ ) sofreram efeito significativo da interação tratamento $\mathrm{x}$ tempo de armazenamento. Já em relação à parte periférica, a variável $L^{*}$ sofreu efeito somente do tempo de armazenamento, e as demais variáveis analisadas $\left(\mathrm{C}^{*} \mathrm{e}^{\circ} \mathrm{H}\right)$ sofreram efeito significativo da interação tratamento $\mathrm{x}$ tempo de armazenamento. Não foi possível ajustar a regressão para as variáveis $L^{*}$ da região lateral, $C^{*} \mathrm{e}$ ${ }^{\circ} \mathrm{H}$ das três regiões avaliadas, pois o $\mathrm{R}^{2}$ calculado apresentou valor insatisfatório (abaixo de $60 \%$ ).

Foi observado aumento da claridade do centro e da lateral das cenouras em todos os tratamentos durante o tempo de armazenamento, sendo que, no final do período de armazenagem, os tratamentos com cobertura de amido em que se adicionou MNFC de cenoura (T1 e T2) apresentaram os menores valores de $L^{*}$ nas duas regiões (figura 8 e tabela 7 , respectivamente). $\mathrm{Na}$ região periférica houve aumento dessa variável, independentemente do tratamento utilizado (figura 9). $O$ aumento do valor $L^{*}$ em cenouras sugere o seu esbranquiçamento, desordem normalmente observada durante armazenamento da raiz fatiada, o que deixa o produto com aspecto envelhecido e não atraente. Para alguns pesquisadores, o esbranquiçamento de cenouras minimamente processadas é devido à desidratação das células superficiais causada pelo processamento (Tatsumi et al., 1993). Outros autores apontam que o motivo do esbranquiçamento é a formação de lignina na superfície dos cortes (Bolin \& Huxsoll, 1999).

Com os resultados do presente trabalho, sugere-se a eficiência do uso de cobertura de amido reforçada com MNFC de cenoura na prevenção do esbranquiçamento.

Para a variável cromaticidade, que indica a pureza da cor, apesar das alterações estatisticamente significativas nas três regiões das cenouras, numericamente tais alterações foram muito pequenas, com poucas possibilidades de interferências visuais a olho nu (tabelas 8, 9 e 10).

Foi observada discreta variação do ângulo Hue da região central das cenouras no decorrer do tempo de armazenamento, independentemente do tratamento (tabela 11). Já para o ângulo Hue das regiões lateral e periférica, foi observado discreto aumento em todos os tratamentos ao longo do armazenamento (tabelas 12 e 13). Entretanto, a variação nos valores de ângulo Hue das três regiões, apesar de estatisticamente significativa, foi numericamente pequena, provavelmente sem efeitos visuais.

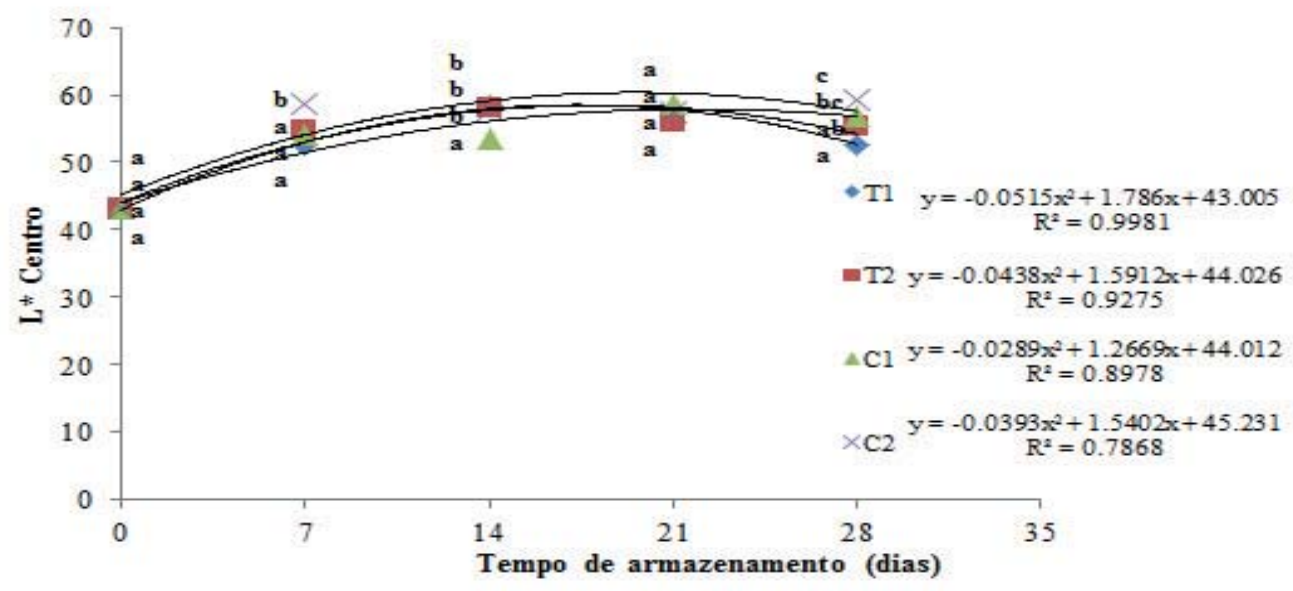

\section{FIGURA 8 - VALORES MÉDIOS DE L* DA REGIÃO CENTRAL DURANTE $O$ ARMAZENAMENTO REFRIGERADO DE CENOURAS MINIMAMENTE PROCESSADAS COM DIFERENTES TRATAMENTOS}

(T1: cenouras recobertas com cobertura comestível de amido + micro/nanofibrilas de cenoura a 20\%; T2: cenouras recobertas com cobertura comestível de amido + micro/nanofibrilas de cenoura a 40\%; C1: cenouras recobertas com cobertura comestível de amido sem micro/nanofibrilas de cenoura; C2: cenouras sem qualquer recobrimento). As médias seguidas pela mesma letra em cada tempo de armazenamento não diferem entre si, pelo teste de Tukey, a $5 \%$ de significância. UFLA, Lavras, 2015. 
TABELA 7 - VALORES MÉDIOS DE CLARIDADE (L*) DA REGIÃO LATERAL DE CENOURAS MINIMAMENTE PROCESSADAS DE DIFERENTES TRATAMENTOS E ARMAZENADAS POR 28 DIAS

\section{L* lateral}

Tempo de armazenamento (dias)

\begin{tabular}{cccc}
\hline T1 & T2 & C1 & C2 \\
\hline $52.20 \mathrm{a}$ & $52.20 \mathrm{a}$ & $52.20 \mathrm{a}$ & $52.20 \mathrm{a}$ \\
$57.69 \mathrm{a}$ & $59.80 \mathrm{a}$ & $58.77 \mathrm{a}$ & $59.32 \mathrm{a}$ \\
$59.55 \mathrm{a}$ & $59.55 \mathrm{a}$ & $60.09 \mathrm{a}$ & $61.84 \mathrm{a}$ \\
\hline $57.74 \mathrm{ab}$ & $56.33 \mathrm{a}$ & $59.66 \mathrm{bc}$ & $62.70 \mathrm{c}$ \\
\hline $58.35 \mathrm{a}$ & $58.92 \mathrm{ab}$ & $60.68 \mathrm{~b}$ & $61.58 \mathrm{~b}$
\end{tabular}

Médias seguidas de letras iguais em cada tempo não diferem entre si, a 5\% de probabilidade, pelo teste de Tukey. T1: cenouras recobertas com cobertura comestível de amido + micro/nanofibrilas de cenoura a 20\%; T2: cenouras recobertas com cobertura comestível de amido + micro/nanofibrilas de cenoura a 40\%; C1: cenouras recobertas com cobertura comestível de amido sem micro/nanofibrilas de cenoura; C2: cenouras sem qualquer recobrimento

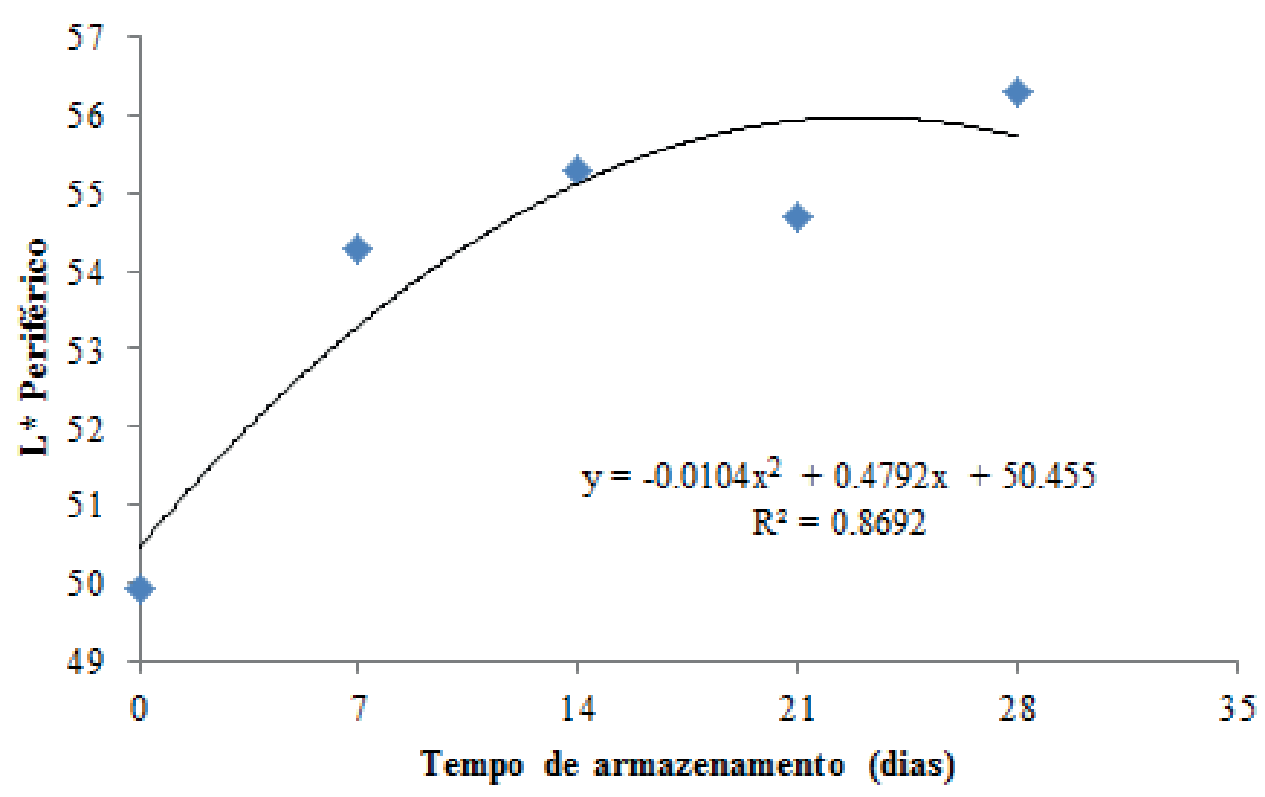

FIGURA 9 - VALORES MÉDIOS DA CLARIDADE (L*) DA REGIÃO PERIFÉRICA DE CENOURAS MINIMAMENTE PROCESSADAS AO LONGO DO ARMAZENAMENTO REFRIGERADO 


\section{TABELA 8 - VALORES MÉDIOS DE C* DA REGIÃO CENTRAL DE CENOURAS MINIMAMENTE PROCESSADAS DE DIFERENTES TRATAMENTOS \\ E ARMAZENADAS POR 28 DIAS}

\begin{tabular}{ccccc} 
Tempo de armazenamento $\begin{array}{c}\text { C* centro } \\
\text { (dias) }\end{array}$ & \multicolumn{4}{c}{ C2 } \\
\cline { 2 - 4 } & T1 & T2 & $37.73 \mathrm{a}$ \\
\hline 0 & $31.73 \mathrm{a}$ & $31.73 \mathrm{a}$ & $31.73 \mathrm{a}$ & $35.01 \mathrm{ab}$ \\
\hline 7 & $34.61 \mathrm{a}$ & $35.23 \mathrm{ab}$ & $40.99 \mathrm{~b}$ & $35.04 \mathrm{a}$ \\
\hline 14 & $33.14 \mathrm{a}$ & $35.00 \mathrm{a}$ & $37.04 \mathrm{a}$ & $36.78 \mathrm{~b}$ \\
\hline 21 & $35.92 \mathrm{~b}$ & $36.52 \mathrm{~b}$ & $29.42 \mathrm{a}$ & $34.75 \mathrm{a}$ \\
\hline
\end{tabular}

Médias seguidas de letras iguais em cada tempo não diferem entre si, a 5\% de probabilidade, pelo teste de Tukey. T1: cenouras recobertas com cobertura comestível de amido + micro/nanofibrilas de cenoura a 20\%; T2: cenouras recobertas com cobertura comestível de amido + micro/nanofibrilas de cenoura a 40\%; C1: cenouras recobertas com cobertura comestível de amido sem micro/nanofibrilas de cenoura; C2: cenouras sem qualquer recobrimento

\section{TABELA 9 - VALORES MÉDIOS DE C* DA REGIÃO LATERAL DE CENOURAS MINIMAMENTE PROCESSADAS DE DIFERENTES TRATAMENTOS E ARMAZENADAS POR 28 DIAS}

\begin{tabular}{ccccc}
\hline & \multicolumn{4}{c}{ C* lateral } \\
Tempo de armazenamento \begin{tabular}{c} 
(dias) \\
\cline { 2 - 4 }
\end{tabular} & $\mathrm{T} 1$ & $\mathrm{C} 2$ & $\mathrm{C} 2$ \\
\hline 0 & $38.40 \mathrm{a}$ & $38.40 \mathrm{a}$ & $38.40 \mathrm{a}$ & $38.40 \mathrm{a}$ \\
\hline 7 & $48.93 \mathrm{~b}$ & $48.34 \mathrm{ab}$ & $49.27 \mathrm{~b}$ & $44.72 \mathrm{a}$ \\
\hline 14 & $45.23 \mathrm{a}$ & $43.27 \mathrm{a}$ & $46.01 \mathrm{a}$ & $46.03 \mathrm{a}$ \\
\hline 21 & $44.35 \mathrm{a}$ & $42.71 \mathrm{a}$ & $48.36 \mathrm{~b}$ & $44.99 \mathrm{ab}$ \\
\hline 28 & $35.88 \mathrm{a}$ & $48.47 \mathrm{~b}$ & $48.05 \mathrm{~b}$ & $47.61 \mathrm{~b}$ \\
\hline
\end{tabular}

Médias seguidas de letras iguais em cada tempo não diferem entre si, a 5\% de probabilidade, pelo teste de Tukey. T1: cenouras recobertas com cobertura comestível de amido + micro/nanofibrilas de cenoura a 20\%; T2: cenouras recobertas com cobertura comestível de amido + micro/nanofibrilas de cenoura a 40\%; C1: cenouras recobertas com cobertura comestível de amido sem micro/nanofibrilas de cenoura; C2: cenouras sem qualquer recobrimento 


\section{TABELA 10 - VALORES MÉdIOS DE C* DA REGIÃO PERIFÉRICA DE CENOURAS MINIMAMENTE PROCESSADAS DE DIFERENTES TRATAMENTOS \\ E ARMAZENADAS POR 28 DIAS}

\begin{tabular}{|c|c|c|c|c|}
\hline \multirow{2}{*}{ Tempo de armazenamento (dias) } & \multicolumn{4}{|c|}{$C^{*}$ periférico } \\
\hline & $\mathrm{T} 1$ & T2 & $\mathrm{C} 1$ & $\mathrm{C} 2$ \\
\hline 0 & $32.84 \mathrm{a}$ & $32.84 \mathrm{a}$ & $32.84 \mathrm{a}$ & $32.84 \mathrm{a}$ \\
\hline 7 & $46.47 \mathrm{c}$ & $43.59 \mathrm{bc}$ & $42.95 \mathrm{ab}$ & $40.16 \mathrm{a}$ \\
\hline 14 & $43.21 \mathrm{ab}$ & $44.31 \mathrm{~b}$ & 40.33 a & $43.82 \mathrm{ab}$ \\
\hline 21 & $38.43 \mathrm{a}$ & $42.89 \mathrm{~b}$ & $41.68 \mathrm{ab}$ & $39.51 \mathrm{a}$ \\
\hline 28 & $44.91 \mathrm{~b}$ & $42.27 \mathrm{ab}$ & $43.59 a b$ & $41.35 \mathrm{a}$ \\
\hline
\end{tabular}

Médias seguidas de letras iguais em cada tempo não diferem entre si, a $5 \%$ de probabilidade, pelo teste de Tukey. T1: cenouras recobertas com cobertura comestível de amido + micro/nanofibrilas de cenoura a $20 \%$; T2: cenouras recobertas com cobertura comestível de amido + micro/nanofibrilas de cenoura a 40\%; C1: cenouras recobertas com cobertura comestível de amido sem micro/nanofibrilas de cenoura; C2: cenouras sem qualquer recobrimento

\section{TABELA 11 - VALORES MÉDIOS DO ÂNGULO HUE ( $\left.{ }^{\circ} H\right)$ DA REGIÃO CENTRAL DE CENOURAS MINIMAMENTE PROCESSADAS AO LONGO DO ARMAZENAMENTO REFRIGERADO}


TABELA 12 - VALORES MÉDIOS DE ÂNGULO HUE DA REGIÃO LATERAL DE CENOURAS MINIMAMENTE PROCESSADAS DE DIFERENTES TRATAMENTOS E ARMAZENADAS POR 28 DIAS

\begin{tabular}{|c|c|c|c|c|}
\hline \multirow{2}{*}{ Tempo de armazenamento (dias) } & \multicolumn{4}{|c|}{${ }^{\circ} \mathrm{H}$ lateral } \\
\hline & $\mathrm{T} 1$ & $\mathrm{~T} 2$ & $\mathrm{C} 1$ & $\mathrm{C} 2$ \\
\hline 0 & $44.12 \mathrm{a}$ & $44,11 \mathrm{a}$ & $44.11 \mathrm{a}$ & $44.11 \mathrm{a}$ \\
\hline 7 & $47.42 \mathrm{a}$ & $52.13 a$ & $53.28 \mathrm{a}$ & $54.43 \mathrm{a}$ \\
\hline 14 & $52.71 \mathrm{a}$ & $53.28 \mathrm{a}$ & $55.58 \mathrm{a}$ & $55.58 \mathrm{a}$ \\
\hline 21 & $52.71 \mathrm{bc}$ & $46.98 \mathrm{a}$ & $49.85 a b$ & $53.86 \mathrm{c}$ \\
\hline 28 & $48.84 \mathrm{a}$ & $53.86 \mathrm{~b}$ & $52.13 \mathrm{ab}$ & $49.24 \mathrm{a}$ \\
\hline
\end{tabular}

Médias seguidas de letras iguais em cada tempo não diferem entre si, a 5\% de probabilidade, pelo teste de Tukey. T1: cenouras recobertas com cobertura comestível de amido + micro/nanofibrilas de cenoura a 20\%; T2: cenouras recobertas com cobertura comestível de amido + micro/nanofibrilas de cenoura a 40\%; C1: cenouras recobertas com cobertura comestível de amido sem micro/nanofibrilas de cenoura; $\mathrm{C} 2$ : cenouras sem qualquer recobrimento

\section{TABELA 13 - VALORES MÉDIOS DE ÂNGULO HUE DA REGIÃO PERIFÉRICA DE CENOURAS MINIMAMENTE PROCESSADAS DE DIFERENTES TRATAMENTOS E ARMAZENADAS POR 28 DIAS}

\begin{tabular}{|c|c|c|c|c|}
\hline \multirow{2}{*}{ Tempo de armazenamento (dias) } & \multicolumn{4}{|c|}{ Hue periférico } \\
\hline & T1 & $\mathrm{T} 2$ & C1 & $\mathrm{C} 2$ \\
\hline 0 & $53.28 \mathrm{a}$ & $53.28 \mathrm{a}$ & $53.28 \mathrm{a}$ & $53.28 \mathrm{a}$ \\
\hline 7 & $55.00 \mathrm{~b}$ & $53.86 a b$ & $55.00 \mathrm{~b}$ & $50.42 \mathrm{a}$ \\
\hline 14 & $52.14 \mathrm{a}$ & $54.43 \mathrm{a}$ & $55.00 \mathrm{a}$ & $54.43 \mathrm{a}$ \\
\hline 21 & $53.86 \mathrm{a}$ & $52.14 \mathrm{a}$ & $54.43 \mathrm{a}$ & $54.43 \mathrm{a}$ \\
\hline 28 & $56.15 \mathrm{~b}$ & $53.28 \mathrm{ab}$ & $51.57 \mathrm{a}$ & $54.43 \mathrm{a}$ \\
\hline
\end{tabular}

Médias seguidas de letras iguais em cada tempo não diferem entre si, a 5\% de probabilidade, pelo teste de Tukey. T1: cenouras recobertas com cobertura comestível de amido + micro/nanofibrilas de cenoura a 20\%; T2: cenouras recobertas com cobertura comestível de amido + micro/nanofibrilas de cenoura a 40\%; C1: cenouras recobertas com cobertura comestível de amido sem micro/nanofibrilas de cenoura; C2: cenouras sem qualquer recobrimento 


\subsection{FENÓLICOS TOTAIS E ATIVIDADE ANTIOXIDANTE TOTAL}

Fenólicos totais, medidos em gramas de ácido gálico por gramas de cenoura, e a atividade antioxidante total, medida em porcentagem de sequestro de radical livre (\% SRL), foram influenciados pela interação tratamento $x$ tempo de armazenamento. Não foi possível ajustar a regressão para a variável fenólicos totais, pois o $\mathrm{R}^{2}$ calculado apresentou valor insatisfatório (abaixo de 60\%).

Observa-se que os tratamentos T1 e T2 apresentaram os maiores valores de fenólicos totais e atividade antioxidante total no final do armazenamento (tabela $14 \mathrm{e}$ figura 10, respectivamente). Esses resultados sugerem que o recobrimento com a cobertura comestível reforçada com MNFC de cenoura possa ser empregado como um aliado na preservação de fenólicos totais e da capacidade antioxidante de cenouras minimamente processadas. A maior eficácia dos revestimentos comestíveis adicionados de micro/nanofibrilas de celulose, na preservação de antioxidantes, está provavelmente relacionada com a melhoria da barreira ao oxigênio ocasionada pelas MNFC de cenoura, fazendo com que seja necessária menor atuação do sistema antioxidante para combater oxidações em presença de oxigênio (Sanchez-Garcia; Lagaron, 2010; Bendahou et al., 2011).

Houve aumento da quantidade de fenólicos totais em quase todos os tratamentos ao longo do armazenamento (tabela 14). Esse aumento pode ser devido ao estresse ocasionado pelo processamento mínimo, já que o corte leva à descompartimentalização de muitos compostos celulares, como algumas enzimas, incluindo a fenilalanina amônia-liase (FAL), que participam da produção de compostos fenólicos diversos, e essa produção de fenólicos é um meio de defesa de vegetais injuriados. Outros autores também observaram aumento de fenóis em cenouras prontas para consumo como uma resposta ao dano induzido pelo processamento (BABIC et al., 1993; HOWARD AND GRIFFIN, 1993; KLAIBER et al., 2005; KENNY \& O'BEIRNE, 2010). Ke e Saltveit (1988) também observaram uma elevação acentuada no conteúdo total de fenóis em alface exposta a vários tipos de estresse (ataque de patógenos, tratamento de etileno).

A capacidade antioxidante de vegetais depende de um grande número de compostos (VINÃ \& CHAVES, 2006). Chu et al. (2000) indicaram que vários fitoquímicos, como flavonoides, compostos fenólicos, aminoácidos, ácido ascórbico, tocoferóis e pigmentos, podem contribuir para a atividade antioxidante total. Assim, a maior atividade antioxidante total observada nos tratamento T1 e T2 no último dia de armazenamento (figura 10) pode ser devido ao maior acúmulo de fenólicos totais nesses tratamentos ao final do armazenamento (tabela 14).

A quantidade de fenóis foi relatada como benéfica para melhorar fitoquímicos de palitos de cenoura (SIMÕES et al., 2009). Cisneros-Zevallos (2003) propuseram o uso de estresses abióticos controlados, tal como ferimento, como uma ferramenta para melhorar o conteúdo fitoquímico de cenouras por induzir a síntese/acúmulo de compostos fenólicos. No entanto, pode ocorrer a percepção de gosto amargo e azedo na cenoura, que tem sido associado com alguns compostos fenólicos (LAFUENTE et al., 1996; TALCOTT et al., 2001; KREUTZMANN et al., 2008). 


\section{TABELA 14 - VALORES MÉDIOS DE FENÓLICOS TOTAIS DE CENOURAS MINIMAMENTE PROCESSADAS DE DIFERENTES TRATAMENTOS E ARMAZENADAS POR 28 DIAS}

\begin{tabular}{|c|c|c|c|c|}
\hline \multirow{2}{*}{$\begin{array}{c}\text { Tempo de amazenamento } \\
\text { (dias) }\end{array}$} & \multicolumn{4}{|c|}{ Fenólicos totais (g EAG.g-1 de cenoura) } \\
\hline & T1 & $\mathrm{T} 2$ & C1 & $\mathrm{C} 2$ \\
\hline 0 & $45.19 b$ & $32.91 \mathrm{a}$ & $32.91 \mathrm{a}$ & $45.19 \mathrm{~b}$ \\
\hline 7 & $47.85 \mathrm{~b}$ & $44.82 \mathrm{ab}$ & $49.45 b$ & $41.14 \mathrm{a}$ \\
\hline 14 & $38.44 \mathrm{a}$ & $45.04 \mathrm{bc}$ & $49.84 \mathrm{c}$ & $40.42 a b$ \\
\hline 21 & $53.41 \mathrm{c}$ & $46.56 \mathrm{bB}$ & $42.26 \mathrm{~b}$ & $36.47 \mathrm{a}$ \\
\hline 28 & $51.93 \mathrm{c}$ & $51.19 \mathrm{bc}$ & $41.54 \mathrm{a}$ & $45.85 \mathrm{ab}$ \\
\hline
\end{tabular}

Médias seguidas de letras iguais em cada tempo não diferem entre si, a 5\% de probabilidade, pelo teste de Tukey. T1: cenouras recobertas com cobertura comestível de amido + micro/nanofibrilas de cenoura a 20\%; T2: cenouras recobertas com cobertura comestível de amido + micro/nanofibrilas de cenoura a 40\%; C1: cenouras recobertas com cobertura comestível de amido sem micro/nanofibrilas de cenoura; $\mathrm{C} 2$ : cenouras sem qualquer recobrimento

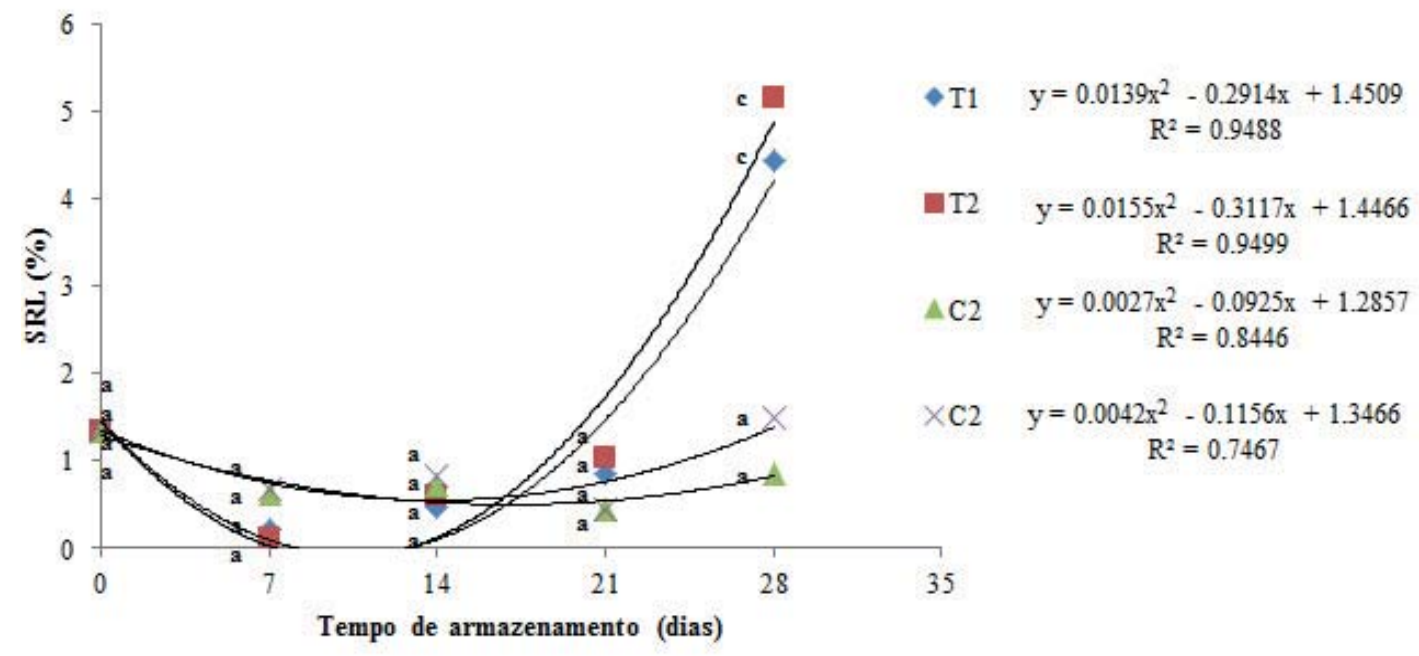

\footnotetext{
FIGURA 10 - VALORES MÉDIOS DE ATIVIDADE ANTIOXIDANTE TOTAL (\% SRL) DURANTE O ARMAZENAMENTO REFRIGERADO DE CENOURAS MINIMAMENTE PROCESSADAS COM DIFERENTES TRATAMENTOS
}

(T1: cenouras recobertas com cobertura comestível de amido + micro/nanofibrilas de cenoura a $20 \%$; T2: cenouras recobertas com cobertura comestível de amido + micro/nanofibrilas de cenoura a 40\%; $\mathrm{C} 1$ : cenouras recobertas com cobertura comestível de amido sem micro/nanofibrilas de cenoura; C2: cenouras sem qualquer recobrimento). As médias seguidas pela mesma letra em cada tempo de armazenamento não diferem entre si, pelo teste de Tukey, a $5 \%$ de significância. UFLA, Lavras, 2015 


\subsection{ASPECTO MICROBIOLÓGICO}

As cenouras minimamente processadas do presente trabalho apresentaram-se microbiologicamente aptas para o consumo em todo o tempo de armazenamento, visto que não apresentaram contagem significativa de fungos filamentosos e leveduras e mostraram-se isentas de Salmonella sp. e de coliformes a $35^{\circ} \mathrm{C}$ e $45^{\circ} \mathrm{C}$, estando, assim, livres também de Escherichia coli. Os resultados estão, então, de acordo com o estabelecido pela legislação vigente, a RDC $n^{\circ} 12$ (BRASIL, 2001). Pela observação desses resultados, é possível afirmar que as etapas do processamento mínimo foram conduzidas em condições higiênico-sanitárias satisfatórias.

Frutas e hortaliças frescas são geralmente incriminadas como veículos de enfermidades alimentares de origem fecal pela presença de Escherichia coli e Salmonella sp., oriundas da água de irrigação e/ou da presença de dejetos no solo ou nos fertilizantes, ou ainda decorrentes de manuseio inadequado e deficiência nos processos de limpeza e sanificação durante o processamento (GANGLIARDI; KARNS, 2000).

A legislação brasileira ainda não fixou padrões microbiológicos para os produtos minimamente processados. Portanto, os padrões utilizados são aqueles que mais se aproximam de tais alimentos, os padrões para "hortaliças frescas, refrigeradas, cortadas ou congeladas, para o consumo direto", que estabelece um limite máximo de $5 \times 10^{2} \mathrm{NMP} \cdot \mathrm{g}^{-1}(2,7$ ciclos log) para coliformes a $45^{\circ} \mathrm{C}$ e a ausência de Salmonella em $25 \mathrm{~g}$ do produto (BRASIL, 2001).

\section{CONCLUSÃO}

Nas condições experimentais do presente trabalho, é possível afirmar que: o uso de cobertura de amido determina menor perda de massa em cenouras minimamente processadas, sendo que coberturas reforçadas com MNFC de cenoura diminuem ainda mais essa perda; a taxa respiratória de cenouras minimante processadas é diminuída quando se faz a aplicação de cobertura de amido reforçada com MNFC de cenoura; o uso de cobertura de amido reforçada com MNFC de cenoura é eficiente na prevenção do esbranquiçamento e na manutenção da atividade antioxidante total, na quantidade de fenólicos totais e de ácidos orgânicos de cenouras minimamente processadas; é de extrema importância que o processamento mínimo seja conduzido em condições higiênico-sanitárias satisfatórias para que o produto esteja apto e seguro para o consumo, ou seja, livre de microrganismos contaminantes durante seu período de vida útil.

\section{ABSTRAT \\ EDIBLE FILM BASED ON STARCH AND CARROT CELLULOSE MICROFIBRILS AND NANOFIBRILS EXTENDS THE LIFE OF MINIMALLY PROCESSED CARROT}

This work aimed to produce minimally processed carrots covered with edible film starchbased reinforced with cellulose microfibrils and nanofibrils (CMNF) extracted from carrot. For the minimal processing, carrots previously sanitized with sodium hypochlorite solution were peeled, sliced, sanitized again and centrifuged. Three covers were prepared at $3 \%$ tapioca starch, two of them were added $5 \%$ carrot CMNF, being a $20 \%$ carrot (ratio of the amount of distilled water amount for the preparation of carrot); and the other $40 \%$ of carrot; the latter formulation was prepared without addition of carrot CMNF. It is generated 4 treatments, $\mathrm{T} 1$ being composed of the carrots with starch coverage containing carrot CMNF 20\%; T2 comprises carrot with starch coverage containing carrot CMNF $40 \%$; $\mathrm{C} 1$ containing carrots coated with starch coverage without carrot CMNF and C2 containing carrots without any coverage. The storage was made in a polypropylene tray inside a freezer. The analyzed characteristics were weight loss, soluble solids, titratable acidity, total soluble sugars, $\mathrm{pH}$, organic acids, respiratory activity, total and soluble pectin, firmness, color, total antioxidant activity, 
total phenolic and microbiological analyzes (filamentous fungi and yeasts, total coliforms and fecal coliforms and Salmonella sp.) every 7 days, during 28 days of storage. The use of starch coverage permitted smaller mass loss of minimally processed carrots, wherein the reinforcement with carrot CMNF further reducing this loss. The use of starch cover reinforced with carrot CMNF was effective to decrease the respiration rate, the prevention of whitening and maintaining the total antioxidant activity, total amount of phenolic and organic acids minimally processed carrots. Carrots showed no significant counts of filamentous fungi and yeasts and absence of Salmonella sp. and coliforms at 35 to $45^{\circ} \mathrm{C}$ and are therefore also free from Escherichia coli.

\section{KEYWORDS: DAUCUS CAROTA; FRESH-CUT; EDIBLE FILM OF STARCH; MICROFIBRILLATED CELLULOSE.}

\section{REFERÊNCIAS}

1 ALI, A.; MUHAMMAD, M. T. M.; SIJAM, K.; SIDDIQUI, Y. Effect of chitosan coatings on the physicochemical characteristics of Eksotika II papaya (Carica papaya L.) fruit during cold storage. Food Chemistry, v. 124, p. 620-626, 2011.

2 ALVES, J. A.; VILAS BOAS, E. V. de B; VILAS BOAS, B. M.; SOUZA, E. C. de. Qualidade de produto minimamente processado à base de abóbora, cenoura, chuchu e mandioquinha-salsa. Ciência e Tecnologia de Alimentos, Campinas, v. 30, n. 3, p. 625-634, jul.-set. 2010.

3 ASSOCIATION OF OFFICIAL ANLYTICAL CHEMISTRY. Official methods of analysis of the Association of Official Analytical Chemistry. 17.ed. Washington, DC, 2000.1410p.

4 AZEREDO, H. M. C.; MATtOSO, L. H. C.; WOOD, D.; WILliAMS, T. G.; AVENA- BUSTILLOS, R. J.; McHUGH, T. H. Nanocomposite Edible Films from Mango Puree Reinforced with Cellulose Nanofibers. Journal of Food Science. v. 74, n. 5, p. 31-35, 2009.

5 AZEREDO, H. M. C.; MIRANDA, K. W. E.; ROSA, M. F.; NASCIMENTO, D. M.; MOURA, M. R. de. Edible films from alginate-acerola puree reinforced with cellulose whiskers. Food Science and Technology, v. 46, p. 294-297, 2012.

6 BABIC, I.; AMIOT, M. J.; NGUYEN-THE, C. Changes in phenolic content in fresh readyto-use shredded carrots during storage. Acta Horticulturae, n. 343, p. 123-129, 1993.

7 BARROS, J. C. S. M.; GOES, A.; MINAMI, K. Condições de conservação pós-colheita de frutos de pimentão (Capsicum annum L.). Scientia Agricola, Piracicaba, v. 51, n. 2, p. 363-368, 1994.

8 BENDAHOU, A.; KADDAMI, H.; ESPUCHE, E.; GOUANVÉ, F.; DUFRESNE, A.. Synergism effect of montmorillonite and cellulose whiskers on the mechanical and barrier properties of natural rubber composites. Macromolecular Materials and Engineering, v. 296, n. 8, p. 760-769, 2011.

9 BOLIN, H.R.; HUXSOLL, C.C. 1991. Control of minimally processed carrot (Daucus carota) surface discoloration caused by abrasion peeling. J Food Sc. 56: 2: 416-418.

10 BRASIL. Ministério da Saúde. Agência Nacional de Vigilância Sanitária. Resolução RDC n¹2, de 2 de janeiro de 2001. Aprova o regulamento técnico para misturas para o preparo de alimentos e alimentos prontos para consumo. Brasília, 2001

11 BRECHT, J. K. Physiology of lightly processed fruits and vegetables. HortScience, v. 30, n. 1, p. 18-21, 1995.

12 BITTER, T.; MUIR, H. M. A modified uronic acid carbazole reaction. Analytical Chemistry, New York, v. 34, p. 330-334, 1962. BRODY, A. L. Envasado de alimentos em atmosferas controladas, modificadas y vazio. Zaragoza: Acribia, 1996. 220 p. CARLIN, F.; NUGYEN-THE, C.; HILBERT, G.; CHAMBROY, Y. Modified atmosphere packaging of fresh "ready-to-use" grated carrots in polymeric films. Journal of Food Science, v. 55, n. 4, p. 1033-1038, 1990.

15 CHERVIN, C.; TRIANTAPHYLIDES, C.; LIBERT, M.F.; SIADOUS, R.; BOISSEAU, P. Reduction of wound-induced respiration and ethylene production in carrot root tissues by gamma irradiation. Postharvest Biology and Technology, $\mathrm{v}$. 2, n. 1, p. 7-17, 1992.

16 CHITARRA, M. I. F.; CARVALHO, V. D. Cenoura: qualidade e industrialização. Informe Agropecuário, v. 10, n. 120 , 1984.

17 CHITARRA, M. I. F.; CHITARRA, A. B. Pós-colheita de frutos e hortaliças: fisiologia e manuseio. 2 ed.rev.ampl. Lavras: UFLA, 2005. 785p.

$18 \mathrm{CHU}$, Y. H., CHANG, CH. L., \& HSU, H. F. Flavonoid content of several vegetables and their antioxidant activity. Journal of the Science of Food and Agriculture, v. 80, p. 561-566, 2000. 
19 CYBULSKA, J.; ZDUNEK, A.; KOZIO, A. The self-assembled network and physiological degradation of pectins in carrot cell walls. Food Hydrocolloids, v. 43, p. 41-50, 2015.

20 DISCHE, Z. General color reactions. In: WHISTLER, R.L.; WOLFRAM, M.L. Carbohydrate chemistry. New York: Academic, 1962, p. 477-512.

21 EMMAMBUX, N. M.; MINNAAR, A. The effect of edible coatings and polymeric packaging films on the quality of minimally processed carrots. Journal of the Science of Food and Agriculture, v. 83, p. 1065-1071, 2003.

22 FERREIRA, D. F. Sistemas para Análise de Variância para Dados (SISVAR). Lavras: UFLA, 1999.

23 GALDON, B. R.; RODRIGUEZ, C. T.; RODRIGUEZ, E. R.; ROMERO, C. D. Organic acid contents in onion cultivars (Allium cepa L.). Journal of Agricultural and Food Chemistry, v. 56, n. 15, p. 6512-6519, 2008.

24 GANGLIARDI, J. V.; KARNS, J. S. Leaching of Escherichia coli 0157: H7 in diverse soils under various agricultural management practices. Applied and Environmental Microbiology, Washington, v. 66, n. 3, p. 877-883, mar. 2000.

25 HOWARD, L.R., GRIFFIN, L.E. Lignin formation and surface discoloration of minimally mprocessed carrot sticks. Journal of Food Science, v. 58, p. 1065-1067, 1993.

26 HUXSOLL, C. C., BOLIN, H. R. Processing and distri-bution alternatives for minimally processed fruits and vegetables. Food Technology. 1989. p. 124-128.

27 INTERNATIONAL COMMISSION ON MICROBIOLOGICAL SPECIFICATIONS FOR FOODS - ICMSF. Microorganisms in foods. 2. ed. Toronto: University of Toronto, 1982. $436 \mathrm{p}$.

28 IZUMI, H.; WATADA, A.E.; KO, N.P.; DOUGLAS, W. Controlled atmosphere storage of carrots slices, sticks and shreds. Postharvest Biology and Technology, v. 9, n. 2, p. 165-172, 1996.

29 KADER, A. A. Flavor quality of fruits and vegetables. Journal of the Science of Food and Agriculture, v. 88, n. 11, p. 1863-1868, 2008.

30 KATO-NOGUSHI, H., WATADA, A. E. Citric acid reduces the respiration of fresh-cut carrots. HortScience, v. 32, n. 1, p. 136, 1997

31 KLAIBER, R.G., BAUR, S., KOBLO, A., CARLE, R. Influence of washing treatment and storage atmosphere on phenylalanine ammonia-lyase activity and phenolic acid content of minimally processed carrot sticks. Journal of Agricultural and Food Chemistry, v. 53, n. 4, p. 1065-1072, 2005.

32 KE, D.; SALTVEIT, M. E. Plant hormone interaction and phenolic metabolism in the regulation of russet spotting in iceberg lettuce. Plant Physiology, v. 88, p. 1136-1140, 1988.

33 KENNY, O.; O'BEIRNE, D. Antioxidant phytochemicals in fresh-cut carrot disks as affected by peeling method. Postharvest Biology and Technology, v. 58, p. 247-253, 2010.

34 KREUTZMANN, S., CHRISTENSEN, L.P., EDELENBOS, M. Investigation of bitterness in carrots (Daucus carota L.) based on quantitative chemical and sensory analyses. Food Science and Technology, v. 41, n. 2, p. 193-205, 2008.

35 KROCHTA, J. M.; De MULDER-JOHNSON, C. M. Edible and biodegradable polymer films: Challenges and opportunities. Food Technology, v. 51, p. 61-74, 1997.

36 KUROSAKI, F; TOKITOH, Y.; NISHI, A. Purification and characterization of wall-bound $\beta-1,3-$ glucanases in cultured carrot cells. Plant Science, v. 77, p. 21-28, 1991.

37 KUROSAKI, F; TOKITOH, Y.; NISHI, A. Interaction of extracellular $\beta-1,3-$ glucanase and pectic substances in cell wall matrix of cultured carrot. Plant Science, v. 84, p. 75-82, 1992.

38 LANA, M.M. Aspectos da fisiologia de cenoura minimamente processada. Horticultura Brasileira, Brasília, v. 18, n. 3, p. 154-158, nov. 2000

39 LAFUENTE, M.A., LOPEZ-GALVEZ, G., CANTWELL, M., FA YANG, S. Factors influencing ethylene-induced isocoumarin formation and increased respiration in carrots. Journal of the American Society for Horticultural Science, v. 121, n. 3, p. 537-542, 1996

40 LAI, T. Y.; CHEN, C. H.; LAI, L. S. Effects of Tapioca Starch/Decolorized Hsian-Tsao Leaf Gum-Based Active Coatings on the Quality of Minimally Processed Carrots. Food Bioprocess Technology, v. 6, p. 249-258, 2013.

41 LIMA, K. S. C.; LIMA, A. L. S.; FREITAS, L. C.; DELLA-MODESTA, R. C.; GODOY, R. L. E. Efeito de baixas doses de irradiação nos carotenoides majoritários em cenouras prontas para o consumo. Ciência e Tecnologia de Alimentos, v. 24, n. 2, p. 183-193, abr./jun, 2004.

42 MIHINDUKULASURIYA, S. D. F.; LIM, L.-T. Nanotechnology development in food packaging: A review. Trends in Food Science \& Technology, v. 40, p. 149-167, 2014.

43 MEDINA, P. V. L. Manejo pós-colheita de pimentões e pimentas. Informe Agropecuário, Belo Horizonte, v. 10, n. 113, p. 72-76, maio 1984. 
44 McCREADY, P. M.; McCOMB, E. A. Extration and determination of total pectic material. Analytical Chemistry, Washington, x. 24, n. 12, p. 1586-1588, 1952.

45 McGUIRE, R. G. Reporting of Objective Color Measurements. HortScience, v. 27, p. 1254-1255, 1992.

46 PILON, L. Estabelecimento da vida útil de hortaliças minimamente processadas bob atmosfera modificada e refrigeração. 2003. 111 f. Dissertação (Mestrado em Ciências)-Escola Superior da Agricultura "Luíz de Queiroz", Universidade de São Paulo, Piracicaba, SP.

47 PROGRAMA BRASILEIRO DE MODERNIZAÇÃO DO MERCADO HORTIGRANJEIRO. Disponível em: http://dw.prohort. conab.gov.br/pentaho/Pivot. Acesso em: 01/09/2015.

48 RAGAERT, P.; DEVLIEGHERE, F.; DEBEVERE, J. Role of microbiological and physiological spoilagemechanisms during storage of minimally processed vegetables. Postharvest Biology and Technology, v. 44, p. 185-194, 2007.

49 REIS, K. C. DOS; ELIAS, H. H. DE S.; LIMA, L. C. DE O.; SILVA, J. D.; PEREIRA, J. Pepino japonês (Cucumis sativus L.) submetido ao tratamento com fécula de mandioca. Ciência e Agrotecnologia, Lavras, v. 30, n. 3, p. 487-493, maio/ jun., 2006.

50 RESENDE, J. M.; COELHO, A. F. S.; CASTRO, E. C.; SAGGIN JÚNIOR, O. J.; NASCIMENTO, T.; BENEDETTI, B. C. Modificações sensoriais em cenoura minimamente processada e armazenada sob refrigeração. Horticultura Brasileira, Brasília, v.22, n.1, p. 147-150, jan-mar 2004.

51 RHIM, J-W; PARK, H-M; HA, C-S. Bio-nanocomposites for food packaging applications. Progress in Polymer Science, v. 38, p. $1629-1652,2013$.

52 RUFINO, M.S.M.; ALVES, R.E.; MORAIS, S.M.; SAMPAIO, C.G.; PEREZ-JIMENEZ,J.; SAURA-CALIXTO, F.D. Metodologia científica:Determinação da atividade antixidante total em frutas pela captura do radical livre DPPH. Comunicado Técnico Embrapa. SSN 1679 6535, jul 2007, Fortaleza, CE.

53 SANCHEZ-GARCIA, M. D.; LAGARON, J. M.. On the use of plant cellulose nanowhiskers to enhance the barrier properties of polylactic acid. Cellulose, v. 17, p. 987-1004, 2010.

54 SILVA, N. da; JUNQUIRA, V. C. A.; SILVEIRA, N. F. A.; TANIWAKI, M. H.; SANTOS, R. F. S. dos; GOMES, R. A. R. Manual de Métodos de Análises Microbiológicas de Alimentos. 3 ed. São Paulo: Livraria Varela, 2007. 552p.

55 SIMÕES, A.D.N., TUDELA, J.A., ALLENDE, A., PUSCHMANN, R., GIL, M.I. Edible coatings containing chitosan and moderate modified atmospheres maintain quality and enhance phytochemicals of carrot sticks. Postharvest Biology and Technology, v. 51, n. 3, p. 364-370, 2009.

56 SPAGNOL, W. A; PARK, K. J.; SIGRIST, J. M. M. Taxa de respiração de cenouras minimamente processadas e armazenadas em diferentes temperaturas. Ciência e Tecnologia de Alimentos, Campinas, v.26, n. 3, p. 550-554, jul.set. 2006.

57 STRANGHETTI, M. de P.; SABIO, R. P.; DELEO, J. P. B. Cenoura. Hortfrut Brasil, ago/2015. Disponível em: http://www. cepea.esalq.usp.br/hfbrasil/edicoes/148/full.pdf. Acesso em: 31/08/2015.

58 TAIZ, L.; ZEIGER, E. Fisiologia Vegetal. 4. ed. Porto Alegre: Artmed, 2009. 848p.

59 TALCOTT, S.T., HOWARD, L.R., BRENES, C.H., 2001. Factors contributing to taste and quality of commercially processed strained carrots. Food Research International, v. 34, n. 1, p. 31-38, 2001.

60 TATSUMI, Y.; WATADA, A.E; LING, P.P. Sodium chlorine treatment or waterjet slicing effects on white tissue development os carrot sticks. J Food Sci. 58: 6: 1390-1392, 1993.

61 VICENTINI, N. M.; CASTRO, T. M. R.; CEREDA, M. P. Influência de películas de fécula de mandioca na qualidade pós-colheita de frutos de pimentão (Capsicum annuum L.). Ciência e Tecnologia de Alimentos, Campinas, v. 19, n. 1, p. 127-130, jan./fev. 1999.

62 VINÃ, S. Z.; CHAVES, A. R. Antioxidant responses in minimally processed celery during refrigerated storage. Food Chemistry, v. 94, p. 68-74, 2006.

63 WATERHOUSE, A. L. Determination of total phenolics. In: Current protocols in food analytical chemistry, Supplement 6 , Unit 11.1.1 - 11.1.8. Wiley, New York, 2002.

\section{AGRADECIMENTOS}

Os autores agradecem a Capes (Coordenação de Aperfeiçoamento de Pessoal de Nível Superior), a agência federal brasileira de apoio e avaliação da educação superior; o Conselho Nacional de Desenvolvimento Científico e Tecnológico (CNPq); e a Fundação de Amparo à Pesquisa do Estado de Minas Gerais (Fapemig), a fundação de pesquisa de Minas Gerais, pelo apoio financeiro. 